\title{
Cloud-Aerosol Transport System (CATS) 1064 nm calibration and validation
}

\author{
Rebecca M. Pauly ${ }^{1, a}$, John E. Yorks ${ }^{2}$, Dennis L. Hlavka ${ }^{1}$, Matthew J. McGill ${ }^{2}$, Vassilis Amiridis ${ }^{3}$, Stephen P. Palm ${ }^{1}$, \\ Sharon D. Rodier ${ }^{4}$, Mark A. Vaughan ${ }^{5}$, Patrick A. Selmer ${ }^{1}$, Andrew W. Kupchock ${ }^{1}$, Holger Baars ${ }^{6}$, and \\ Anna Gialitaki ${ }^{3}$ \\ ${ }^{1}$ Science Systems and Applications Inc., Lanham, 20706, USA \\ ${ }^{2}$ NASA Goddard Space Flight Center, Code 612, Greenbelt, 20771, USA \\ ${ }^{3}$ National Observatory of Athens, Institute for Astronomy, Astrophysics, Space Application and \\ Remote Sensing, Athens, Greece \\ ${ }^{4}$ Science Systems and Applications Inc., Hampton, 23666, USA \\ ${ }^{5}$ NASA Langley Research Center, Mail Stop 475, Hampton, VA 23681-2199, USA \\ ${ }^{6}$ Leibniz Institute for Tropospheric Research (TROPOS), Remote Sensing and Atmospheric Processes , Leipzig, Germany \\ ${ }^{a}$ now at: National Renewable Energy Laboratory, Water Power Program, Golden, CO 80401, USA
}

Correspondence: Rebecca M. Pauly (rpauly90@gmail.com)

Received: 24 April 2019 - Discussion started: 12 June 2019

Revised: 12 September 2019 - Accepted: 23 September 2019 - Published: 28 November 2019

\begin{abstract}
The Cloud-Aerosol Transport System (CATS) lidar on board the International Space Station (ISS) operated from 10 February 2015 to 30 October 2017 providing rangeresolved vertical backscatter profiles of Earth's atmosphere at 1064 and $532 \mathrm{~nm}$. The CATS instrument design and ISS orbit lead to a higher $1064 \mathrm{~nm}$ signal-to-noise ratio than previous space-based lidars, allowing for direct atmospheric calibration of the $1064 \mathrm{~nm}$ signals. Nighttime CATS version 300 data were calibrated by scaling the measured data to a model of the expected atmospheric backscatter between 22 and $26 \mathrm{~km}$ a.m.s.l. (above mean sea level). The CATS atmospheric model is constructed using molecular backscatter profiles derived from Modern-Era Retrospective analysis for Research and Applications, Version 2 (MERRA2) reanalysis data and aerosol scattering ratios measured by the Cloud-Aerosol Lidar with Orthogonal Polarization (CALIOP). The nighttime normalization altitude region was chosen to simultaneously minimize aerosol loading and variability within the CATS data frame, which extends from 28 to $-2 \mathrm{~km}$ a.m.s.l. Daytime CATS version 3-00 data were calibrated through comparisons with nighttime measurements of the layer-integrated attenuated total backscatter (iATB) from strongly scattering, rapidly attenuating opaque cirrus clouds.
\end{abstract}

The CATS nighttime $1064 \mathrm{~nm}$ attenuated total backscatter (ATB) uncertainties for clouds and aerosols are primarily related to the uncertainties in the CATS nighttime calibration technique, which are estimated to be $\sim 9 \%$. Median CATS V3-00 $1064 \mathrm{~nm}$ ATB relative uncertainty at night within cloud and aerosol layers is $7 \%$, slightly lower than these calibration uncertainty estimates. CATS median daytime $1064 \mathrm{~nm}$ ATB relative uncertainty is $21 \%$ in cloud and aerosol layers, similar to the estimated $16 \%$ $18 \%$ uncertainty in the CATS daytime cirrus cloud calibration transfer technique. Coincident daytime comparisons between CATS and the Cloud Physics Lidar (CPL) during the CATS-CALIPSO Airborne Validation Experiment (CCAVE) project show good agreement in mean ATB profiles for clearair regions. Eight nighttime comparisons between CATS and the Polly ${ }^{\mathrm{XT}}$ ground-based lidars also show good agreement in clear-air regions between 3 and $12 \mathrm{~km}$, with CATS having a mean ATB of $19.7 \%$ lower than Polly ${ }^{X T}$. Agreement between the two instruments $(\sim 7 \%)$ is even better within an aerosol layer. Six-month comparisons of nighttime ATB values between CATS and CALIOP also show that iATB comparisons of opaque cirrus clouds agree to within $19 \%$. Overall, CATS has demonstrated that direct calibration of the 
$1064 \mathrm{~nm}$ channel is possible from a space-based lidar using the atmospheric normalization technique.

\section{Introduction}

Lidar plays a crucial role in observing the Earth's atmosphere as it enhances our understanding of the roles clouds and aerosols play in the climate system by providing vertical profiles of backscatter coefficient and other optical properties. Lidars have been utilized to study the vertical distribution and injection heights of smoke plumes (e.g., McGill et al., 2003; Wang et al., 2013; Rajapakshe et al., 2017), properties and transport of mineral dust aerosols (e.g., Papayannis et al., 2009; Yang et al., 2013; Haarig et al., 2017), and layer and optical properties of clouds (e.g., Yorks et al., 2011; Avery at al., 2012; Haarig et al., 2016; Noel et al., 2018). Lidar, particularly from a spaceborne platform, has the capability to provide these vertical profiles of cloud and aerosol optical properties globally.

To derive optical properties of clouds and aerosols from backscatter lidar systems, the signal must be accurately calibrated. While various methods have been used for calibrating lidar-measured signal, the preferred method is the Rayleigh normalization technique, with minor if any corrections for aerosol contributions, as described in Russell et al. (1979). Ground-based lidars (e.g., Micro-Pulse Lidar Network (MPLNet); Welton et al., 2001) calibrate by normalizing their signal to the molecular profile but require knowledge of the aerosol optical depth of the atmosphere between the instrument and the calibration region (Welton et al., 2002). Since the MPLNet lidar sites are colocated with Aerosol Robotic Network (AERONET) (Holben et al., 1998) sites, the aerosol optical depth can be derived directly from the AERONET column optical depths measured by sun photometers.

High-altitude airborne and spaceborne lidars have the benefit of weak aerosol loading in the atmosphere between the instrument and the calibration region. Spaceborne lidars, e.g., Lidar In-Space Technology Experiment (LITE) (Winker et al., 1996), the Geoscience Laser Altimeter System (GLAS) (Spinhirne et al., 2005), and the Cloud-Aerosol Lidar with Orthogonal Polarization (CALIOP) (Winker et al., 2010), have used a similar Rayleigh normalization technique to calibrate their $532 \mathrm{~nm}$ signals. Due to the weaker molecular signal-to-noise ratio (SNR) at $1064 \mathrm{~nm}$ compared to $532 \mathrm{~nm}$ for these instruments, calibration techniques for the $1064 \mathrm{~nm}$ attenuated total backscatter (ATB) calibration are based on the $532 \mathrm{~nm}$ ATB calibration (Vaughan et al., 2019).

Operationally, LITE did not calibrate its $1064 \mathrm{~nm}$ channel. GLAS and CALIOP use variants of the cirrus cloud calibration scheme proposed by Reagan et al. (2002). The CALIOP algorithms first calibrate the $532 \mathrm{~nm}$ data by normalizing the data between 36 and $39 \mathrm{~km}$ (Kar et al., 2018) to a modeled molecular density profile derived from the
Modern-Era Retrospective analysis for Research and Applications, Version 2 (MERRA-2) reanalysis meteorological profiles (Gelaro et al., 2017). The $1064 \mathrm{~nm}$ signal is calibrated utilizing the $532 \mathrm{~nm}$ calibrated signal within cirrus clouds. Clouds are identified for use in the calibration algorithm based on thresholds applied to the magnitude of the $532 \mathrm{~nm}$ layer-integrated attenuated backscatter $\left(\mathrm{sr}^{-1}\right)$, cloud base and top altitudes, cloud temperature, and the layerintegrated $532 \mathrm{~nm}$ volume depolarization ratio (Vaughan et al., 2019). Using cirrus comprised of ice crystals assumed to be larger than the lidar wavelength ensures that the incloud backscatter coefficients at 1064 and $532 \mathrm{~nm}$ are essentially identical (Reagan et al., 2002; Vaughan et al., 2010; Haarig et al., 2016), thus enabling calculation of a 532-to1064 calibration scale factor for each qualifying cirrus cloud identified in the CALIPSO backscatter data. These calibration scale factors are then composited into a continuous time history using a two-dimensional moving-window averaging scheme that spans multiple orbits. For any individual profile, the CALIPSO $1064 \mathrm{~nm}$ calibration coefficient is simply the product of the interpolated instantaneous value of the scale factor time history and the corresponding $532 \mathrm{~nm}$ calibration coefficient (Vaughan et al., 2019).

The Cloud-Aerosol Transport System (CATS) (McGill et al. 2015) on board the International Space Station (ISS) is unique in that its strong nighttime SNR at $1064 \mathrm{~nm}$ enables calibration of the $1064 \mathrm{~nm}$ nighttime data directly by normalizing the range-corrected signal to a modeled molecular profile. There are three factors that enable the direct calibration of CATS $1064 \mathrm{~nm}$ data. First, CATS utilizes photoncounting detectors that provide sufficient detection sensitivity at $1064 \mathrm{~nm}$ (Yorks et al., 2016). Second, the combination of low pulse energies $(1-2 \mathrm{~mJ})$ and higher repetition rate $(4-5 \mathrm{kHz})$ lead to a higher output power $(\sim 8 \mathrm{~W})$ than all previous spaceborne lidars. Third, the CATS orbit on the ISS is considerably lower than other spaceborne lidars at $\sim 405 \mathrm{~km}$ a.m.s.l. Section 2 of this paper discusses the CATS instrument, algorithms, and calibration. Section 3 discusses the uncertainties in the CATS calibration coefficients and attenuated total backscatter (ATB) measurements. Comparisons with airborne, ground-based, and spaceborne lidar are presented in Sect. 4. Concluding remarks are given in Sect. 5.

\section{The CATS instrument}

CATS is an elastic backscatter lidar on board the ISS, which operated nearly continuously from 10 February 2015 to 30 October 2017. With the ISS $51^{\circ}$ inclination orbit, CATS provided diurnally varying measurements of clouds and aerosols. Over the course of the CATS lifetime, it operated in two modes. The first, mode 7.1, featured two fields of view with backscatter and depolarization information at both 1064 and $532 \mathrm{~nm}$. Mode 7.1 utilized laser 1, which had a repetition ratio of $5 \mathrm{kHz}$ and an output energy of $\sim 1 \mathrm{~mJ}$ per pulse 
at both wavelengths. CATS operated in mode 7.1 for only $40 \mathrm{~d}$ due to a failure in laser 1 electronics, after which operations switched to mode 7.2. Mode 7.2 featured a single field of view, backscatter profiles at 1064 and $532 \mathrm{~nm}$, and depolarization measurements at $1064 \mathrm{~nm}$. Mode 7.2 used the second laser, which had a repetition ratio of $4 \mathrm{kHz}$ and an output energy of $\sim 2 \mathrm{~mJ}$ per pulse at $1064 \mathrm{~nm}$. The different laser repetition rates yielded signal-folding windows (see Sect. 2.1 for more details) of $30 \mathrm{~km}$ (mode 7.1$)$ and $37.5 \mathrm{~km}$ (mode 7.2). To comply with ISS data rate limitations and simplify data system designs, the CATS data frame was set to -2.0 to $28 \mathrm{~km}$ (the lower of the signal-folding windows of the two modes) for all modes. CATS data are reported at a vertical sampling interval of $60 \mathrm{~m}$ for both modes, with a temporal resolution of $20 \mathrm{~Hz}(\sim 350 \mathrm{~m}$ horizontal given the speed of the ISS), which required onboard integration of 200 laser shots in mode 7.2 (250 for mode 7.1). Since the majority of the CATS data were collected in mode 7.2, this paper primarily focuses on results from mode 7.2, although the calibration process is the same for both.

CATS version 3-00 data products, which are the focus of this paper, consist of two primary data-processing levels. To create Level 1 (L1) data products, the raw CATS signal is range corrected, geolocated, corrected for detector nonlinearity, and normalized to laser energy (measured on board and averaged/reported at $20 \mathrm{~Hz}$ ), producing the normalized relative backscatter (NRB). The NRB, in units of squared kilometers per joule $\left(\mathrm{km}^{2} \mathbf{J}^{-1}\right)$ counts, can be defined as

$\operatorname{NRB}(r)=\frac{\left\{\left[N_{\mathrm{S}}(r) \times D\right]-N_{\mathrm{B}}\right\} r^{2}}{E}$,

where $r$ is the range (meters), $N_{\mathrm{S}}$ is the geolocated CATS signal (photon counts), $D$ is the correction term for detector nonlinearity (unitless), and $E$ is the laser energy (Joules). Since the detectors employed by CATS have a dead time of 28 to $30 \mathrm{~ns}$ for a discriminator maximum count rate on the order of $30 \mathrm{MHz}$, and CATS has a photon count rate of less than $35 \mathrm{MHz} 99 \%$ of the time below $28 \mathrm{~km}, D$ is less than 1.10 for most atmospheric profiles (Yorks et al., 2015). $N_{\mathrm{B}}$ is the photon counts from solar background, which can be determined by averaging the background signal acquired after the laser signal attenuated by Earth's surface and after the correction for the signal folding. Next, the signal is calibrated using the molecular profile derived from MERRA-2 meteorological reanalysis data. The calibration coefficients, determined through the methods described below, can be found in each CATS L1B data file (also called granule). For Level 2 (L2) data products, aerosol and cloud layers are detected and optical properties are determined. Descriptions of the L2 algorithms are beyond the scope of this paper, but more information about both L1 and L2 processing algorithms can be found in the CATS Algorithm Theoretical Basis Document (ATBD) (Yorks et al., 2015).

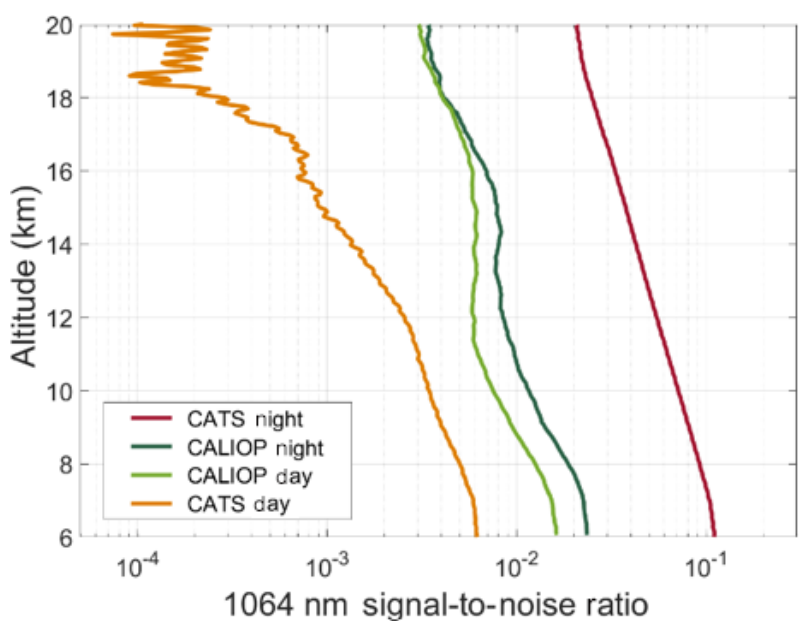

Figure 1. The CATS and CALIOP $1064 \mathrm{~nm}$ signal-to-noise ratios for both daytime and nighttime data. The CATS nighttime SNR is nearly an order of magnitude greater than CALIOP (day and night), while the CATS daytime SNR is lower than CALIOP. The CATS profiles are computed for data acquired at a laser pulse rate of $4 \mathrm{kHz}$ and averaged to $350 \mathrm{~m}$ horizontally. The CALIOP profiles are calculated for individual laser pulses acquired at $20.16 \mathrm{~Hz}$, equivalent to a horizontal resolution of $335 \mathrm{~m}$. The initial vertical resolution for all profiles is $60 \mathrm{~m}$. All profiles are subsequently smoothed using a $2 \mathrm{~km}$ (34 point) running average.

\subsection{CATS nighttime calibration}

CATS exhibits high nighttime $1064 \mathrm{~nm}$ SNR, enabling $1064 \mathrm{~nm}$ attenuated total backscatter (ATB) direct calibration by normalizing the CATS signal to the Rayleigh profile corrected for aerosol contributions. Figure 1 shows the CATS $1064 \mathrm{~nm}$ SNR for both night and day as compared to those of CALIOP $1064 \mathrm{~nm}$. The CATS nighttime SNR is approximately an order of magnitude higher than that of CALIOP throughout the measurement column. On the other hand, the daytime CATS SNR is approximately a factor of 2 lower than CALIOP's, necessitating a different calibration technique for daytime data, as described in Sect. 2.2. The CATS nighttime signal is calibrated in the region between 22 and $26 \mathrm{~km}$ a.m.s.l. There are two factors that determined this altitude region: (1) the CATS data frame is -2 to $28 \mathrm{~km}$ a.m.s.l. because the CATS laser 1 repetition rate of $5 \mathrm{kHz}$ creates a $30 \mathrm{~km}$ atmospheric window for scattering from a single laser shot, and (2) testing of the highest possible altitude regions (based on no. 1) showed better performance in the $22-26 \mathrm{~km}$ than the $23-27 \mathrm{~km}$ region. While this altitude region provides sufficient molecular scattering for the Rayleigh normalization technique, the aerosol loading in the lower stratosphere $(22-26 \mathrm{~km})$ is also higher than the $36-39 \mathrm{~km}$ region used to calibrate $532 \mathrm{~nm}$ CALIOP data. To improve the accuracy of the CATS nighttime calibration, the aerosol loading in the calibration region must be quantified, along with the ozone transmission profile, molecular 
backscatter profile, and polarization gain ratio (PGR). Additionally, the background signal must be removed from the data. Since the CATS data are normalized to the Rayleigh profile corrected for aerosol contributions, more so than previous projects that have employed a similar technique, we will refer to the CATS nighttime calibration technique as the "atmospheric normalization technique" in this paper.

The nighttime atmospheric normalization technique is complicated by molecular folding of the raw signal caused by CATS' high-repetition-rate laser. Molecular folding refers to the fact that the CATS raw photon count at altitude, $z$, where $z<28 \mathrm{~km}$, has scattering contributions from the atmosphere at heights $z+N_{x} . N=1,2,3$, etc., where $x$ equals $37.5 \mathrm{~km}$ for mode 7.2 since laser 2 had a repetition rate of $4 \mathrm{kHz}$. The implications of this are that the region below the surface return (from -2.0 to $0.0 \mathrm{~km}$ ), which is used for determining the background signal, also has molecular signal from 37.5 to $39.5 \mathrm{~km}$. If this folded signal is not removed from the background signal, most of the signal in the calibration region will be removed by the background removal process. A correction term was implemented to account for this molecular folding. The folded signal is computed from instrument parameters and the known molecular attenuated backscatter cross section between 37.5 and $39.5 \mathrm{~km}$ and subtracted from the signal in the background region ( 0.0 to $-2.0 \mathrm{~km}$ below the ground). For nighttime data, this can affect the profile slope of the average signal above $20 \mathrm{~km}$. If too much folding is removed, the slope will be greater than the molecular slope, and if too little is removed, the average signal slope will be less than the molecular slope. In the data processing, a scaling factor in the folding equation is adjusted until the slope difference is less than $3.5 \%$. The potential error introduced by this correction is discussed further in Sect. 3. For more information about molecular folding corrections, see the CATS ATBD (Yorks et al., 2015).

Depending on the profile location of the calibration region, the aerosol loading at those altitudes can introduce uncertainties in the computation of the calibration coefficient of any lidar system (Powell et al., 2009; Vernier et al., 2009; Kar et al., 2018). Thus, the CATS algorithm improves the calibration accuracy by incorporating a range-dependent particulate scattering ratio (unitless fraction), $R_{\lambda}(r)=\frac{\beta_{\mathrm{m}}(r)+\beta_{\mathrm{p}, \lambda}(r)}{\beta_{\mathrm{m}, \lambda}(r)}=$ $1+\frac{\beta_{\mathrm{p}, \lambda}(r)}{\beta_{\mathrm{m}, \lambda}(r)}$, where $\lambda$ indicates the wavelength of the measurement and $\beta_{\mathrm{m}, \lambda}(r)$ and $\beta_{\mathrm{p}, \lambda}(r)$ are, respectively, the volume backscatter coefficients for molecules and particulates (units $\mathrm{km}^{-1} \mathrm{sr}^{-1}$ ) at range $r$, with particulates being understood to represent either cloud or aerosol particles. No space-based sensors provide stratospheric particulate scattering ratios at $1064 \mathrm{~nm}$ on a global scale. However, since robust estimates of the $532 \mathrm{~nm}$ scattering ratios in the CATS vertical calibration zone can be readily derived from the CALIOP V4 Level 1 data, the CALIOP data are used to estimate the spatially and temporally varying $1064 \mathrm{~nm}$ scattering ratio at these altitudes (Fig. 2). Every 15 d, the CATS team computed $30 \mathrm{~d}$ zonal averages of the CALIOP $532 \mathrm{~nm}$ scattering ratios between 22 and $26 \mathrm{~km}$. Given an estimate of the particulate (i.e., aerosol) backscatter color ratio (unitless fraction),

$\chi_{\mathrm{p}}=\frac{\beta_{\mathrm{p}, 1064}(r)}{\beta_{\mathrm{p}, 532}(r)}$.

The $1064 \mathrm{~nm}$ scattering ratios can then be computed from the $532 \mathrm{~nm}$ scattering ratios, which have been interpolated to the CATS vertical resolution, using

$R_{1064}(r)=1+\frac{\chi_{\mathrm{p}} \beta_{\mathrm{m}, 532}(r)\left(R_{532}(r)-1\right)}{\beta_{\mathrm{m}, 1064}(r)}$,

where, following Hair et al. (2008), $\chi_{\mathrm{P}}=0.40$ is taken as a constant for the aerosol loading in the upper troposphere/lower stratosphere. This value is originally derived from data shown in Spinhirne et al. (1997). Sulfate aerosols are potentially the largest contributor to the stratospheric aerosol loading (SPARC-ASAP, 2006; Vernier et al., 2015; Kresmer et al., 2016), and this value is also consistent with lower tropospheric measurements of sulfate aerosols (Groß et al., 2013). The ozone transmission, $T_{\mathrm{o}}^{2}(r)$, is determined from the MERRA-2 ozone mass mixing ratios and meteorological profiles. The ozone transmission is calculated using

$T_{\mathrm{o}}^{2}(\lambda, r)=\exp \left[-2 c_{\mathrm{o}}(\lambda) \int_{H}^{r} \varepsilon_{\mathrm{o}}\left(r^{\prime}\right) \mathrm{d} r^{\prime}\right]$,

where $\varepsilon_{\mathrm{O}}(r)$ is the column density of ozone and $c_{\mathrm{O}}(\lambda)$ is the Chappius ozone absorption coefficient (in $\mathrm{cm}^{-1}$ ) obtained from a lookup table found in Iqbal (1984). The $1064 \mathrm{~nm}$ ozone coefficient is $\sim 0.0 \mathrm{~cm}^{-1}$ leading to the ozone transmission at $1064 \mathrm{~nm}$ being 1.0 and negligible to the $1064 \mathrm{~nm}$ signal calibration.

The molecular backscatter coefficient is calculated using the relationship to atmospheric temperature and pressure (Collins and Russell, 1976), with

$\beta_{\mathrm{M}}=\frac{p}{K T}\left(5.45 \times 10^{-32}\right)\left(\frac{\lambda}{550}\right)^{-4.09}$,

where $T$ is temperature $(\mathrm{K}), p$ is the atmospheric pressure $\left(P_{\mathrm{a}}\right)$, and $K$ is the Boltzmann constant $\left(\mathrm{m}^{2} \mathrm{~kg} \mathrm{~s}^{-2} \mathrm{~K}^{-1}\right)$. The atmospheric profiles of temperature and pressure are obtained from the MERRA-2 reanalysis data. The atmospheric profiles are interpolated to the $60 \mathrm{~m}$ vertical resolution of the CATS lidar backscatter data. The molecular extinction coefficient $\left(\sigma_{\mathrm{M}}\right.$, units $\left.\mathrm{km}^{-1}\right)$ is determined though the following relationship:

$\sigma_{\mathrm{M}}=\beta_{\mathrm{M}}\left(\frac{8}{3}\right) \pi$

The PGR, which is reported in the Level 1B data files as metadata, is required to account for relative gain between 
(a)

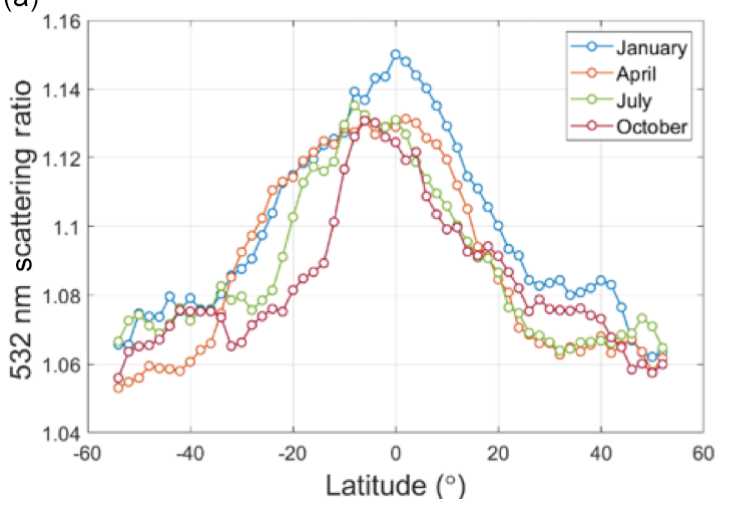

(b)

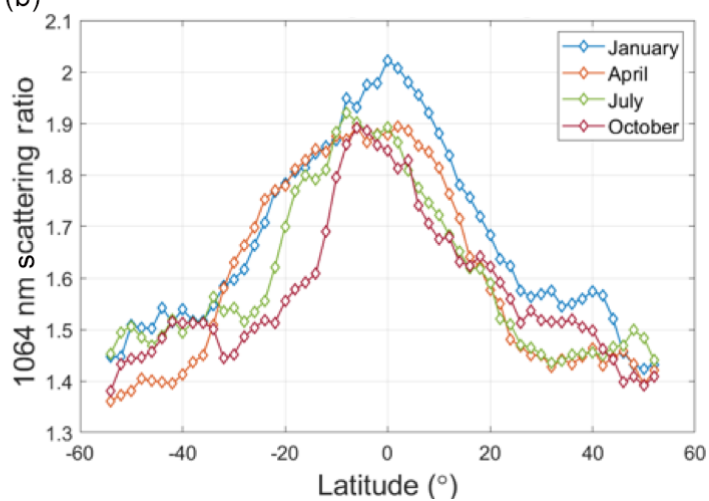

Figure 2. The $532 \mathrm{~nm}$ scattering ratios measured by CALIOP within the CATS calibration region (a) and the $1064 \mathrm{~nm}$ scattering ratios estimated from the $532 \mathrm{~nm}$ retrievals (b) from 2016. These plots show the temporal and latitudinal variability within the calibration region where $1064 \mathrm{~nm}$ estimated scattering ratios can range from below 1.4 to above 2.0 depending on the time of year and geographical location.

the CATS parallel and perpendicular channels in the receiver. The PGR is determined from the scattered solar background radiation ratio of the parallel-to-perpendicular channels from dense cirrus clouds following the methodology from Liu et al. (2004). It can be assumed that the difference in solar background counts between the two channels is negligible because scattered solar radiation from dense ice clouds is unpolarized (Liou et al., 2000). The CATS PGR is computed through the ratio of the sum of all parallel and perpendicular profiles in a daytime granule containing dense ice clouds. The profiles with dense ice clouds used in this computation, which are similar to those used in the CALIOP $1064 \mathrm{~nm}$ calibration technique as outlined in Vaughan et al. (2010), are identified through the following criteria:

1. Midcloud temperature $<-35^{\circ} \mathrm{C}$, as reported by MERRA-2.

2. Cloud-layer-integrated ATB (iATB): $0.008<$ iATB $<$ $0.044 \mathrm{sr}^{-1}$.

3. Layer-integrated depolarization ratio NRB data $\left(\delta_{1064}\right)$ : $0.3<\delta_{1064}<0.8$, where

$$
\delta_{1064}=\frac{\sum_{\text {layer }} \mathrm{NRB}_{\text {perp }} \mathrm{PGR}_{\text {hist }}}{\sum_{\text {layer }} \mathrm{NRB}_{\mathrm{par}}}
$$

(where $\mathrm{PGR}_{\text {hist }}$ is a historical PGR value).

4. Cloud optical depth $>1.75$ (estimated using the iATB and assumed lidar ratio of $25 \mathrm{sr}$ ).

These criteria were only used to identify cirrus clouds that would be suitable for calculating the PGR. Historical calibration coefficients and PGR values were used to estimate iATB, depolarization ratio, and optical depth. These historical values were not applied to the raw data during the actual
PGR calculation. Because the CATS instrument ceased operation prior to the processing of CATS V3-00 data, a singular yearly average PGR value was used for 2015, 2016, and 2017 equaling $0.9839,0.9768$, and 0.9708 respectively. The PGR is applied as a multiplicative factor to the perpendicular channel NRB data. The perpendicular (multiplied by the PGR) and parallel NRB data are added together to arrive at the total NRB.

A single calibration coefficient for nighttime data is applied to the NRB profile on a per file, or granule, basis, using the methodology as follows to obtain the attenuated total backscatter $\left(\mathrm{km}^{-1} \mathrm{sr}^{-1}\right)$ profiles. To prepare for calibration, the CATS night granules are separated into six segments averaging 7.8 min each, depending on the length of the granule. Granules are the files for the CATS data that span about half of the ISS orbit and contain only daytime or only nighttime observations. For calibration, the total NRB profile is averaged within each segment. The average total NRB profile is divided by the ozone transmission and scattering ratio of the corresponding wavelength as a function of height. The profiles of the calibration coefficient $(C)$, in units of $\mathrm{km}^{3} \mathrm{sr} \mathrm{J}^{-1}$ counts, for each segment within a file are determined by normalizing the mean NRB signal which has been corrected for aerosol loading and the ozone transmission, $\beta_{\mathrm{CN}}$, to the mean molecular backscatter $\left(\beta_{\mathrm{M}} T_{\mathrm{M}}^{2}\right)$ (Russell et al., 1979; Del Guasta, 1998; McGill et al., 2007; Powell et al., 2009), via

$C_{\lambda}(r)=\frac{\left[\frac{\mathrm{NRB}(r)}{T_{\mathrm{O}}^{2}(r) R(r)}\right]}{\beta_{\mathrm{M}}(r) T_{\mathrm{M}}^{2}(r)}=\frac{\beta_{\mathrm{CN}}(r)}{\beta_{\mathrm{M}}(r) T_{\mathrm{M}}^{2}(r)}$.

The final calibration coefficient for the segment is the average coefficient in the calibration region profile (i.e., an average of $C(r)$ from 22 to $26 \mathrm{~km})$. Each coefficient is compared to minimum and maximum threshold values, which vary based on the fluctuations shown in Fig. 3, to determine if the calculated value is within acceptable bounds. If the coefficient is not, it 
is discarded and not used in the final calibration calculation. The calibration thresholds were determined through prior experience calibrating airborne lidar as well as through testing on CATS data during which outliers that negatively impacted the total calibration were identified. All good calibration values within a file are then averaged. On average, $67 \%$ of calibration values within a given granule are accepted and used for determining the final calibration coefficient for that file. If less than $15 \%$ of calibration values are accepted, a default calibration coefficient is used for that granule, computed as the mean of the calibration coefficients from the previous week of data. These files represent $3 \%$ of CATS data, typically when the laser was recently turned on after being off for more than $2 \mathrm{~h}$, and are noted in the quality control flag variable in the CATS L1B data products. The final calibration coefficient, which is also reported in the Level 1B data files, is then applied to all NRB profiles within the granule to compute the ATB.

The time evolution of the CATS nighttime calibration coefficients is correlated with the thermal stability of the cooling loop on the ISS, which in turn is attributed to the changing of the sun's angle with respect to the ISS orbital plane, known as its beta angle. The CATS nighttime calibration coefficients oscillate from $4 \times 10^{8}$ to $1.4 \times 10^{9} \mathrm{~km}^{3} \mathrm{sr} \mathrm{J}{ }^{-1}$ counts with a period of roughly $30-40 \mathrm{~d}$. This oscillation is a result of changes in the CATS laser properties (i.e., wavelength, alignment, etc.) due to thermal instability of the cooling loop. The thermal instability of the cooling loop and instrument was monitored by the cold plate temperature. Figure 3 shows the daily average nighttime calibration coefficient (black x's and black line) and CATS cold plate temperature (blue) for the entire mode 7.2 data set (top, April 2015-October 2017) and for a subset from January to April 2016 (bottom). The changing value of the calculated calibration coefficient follows the same pattern as the cold plate temperature. The daily average nighttime calibration coefficient and cold plate temperature have a correlation coefficient of 0.8066 during the period of January-April 2016.

\subsection{CATS daytime calibration}

Because CATS daytime data exhibit lower SNR due to solar background noise, calibrating the daytime granules through the atmospheric normalization method is not possible. Therefore, the daytime calibration coefficients are determined through calibration transfer from the nighttime calibration (Eq. 9). In previous CATS data versions, the daytime calibration was determined through a manual normalization to the Rayleigh profile corrected for aerosol contributions that required periodic assessment and updates. For V3-00 CATS data, a single daytime calibration coefficient was determined for each calendar month of CATS data through an assessment of the iATB $\left(\mathrm{sr}^{-1}\right)$ in strongly scattering opaque cirrus clouds that have a midlayer temperature colder than $-20^{\circ} \mathrm{C}$ (based on the MERRA-2 reanalysis data) and a layer-integrated de- polarization ratio between 0.25 and 0.7 . Only highly scattering, rapidly attenuating clouds (CATS signal attenuated in $2 \mathrm{~km}$ or less) were used in the assessment.

It was found that using a month of data provided enough data points to compute a calibration value while also reasonably capturing the temporal variability of calibration coefficients. The assessment of cirrus cloud properties was done using V2-01 CATS data in which the layer detection and optical properties algorithms were already run. A layer is classified as opaque if no layer or ground signal is detected below it. The iATB is calculated through the cloud until the point of signal attenuation. For the strongly scattering, rapidly attenuating opaque cirrus selected for the daytime calibration transfer procedure, there should be little difference between nighttime and daytime iATB retrievals. This characteristic of cirrus clouds has been observed in CALIOP data as shown in Young et al. (2018). Young et al.'s CALIOP comparisons of opaque cirrus at $532 \mathrm{~nm}$ showed substantial iATB similarities for both nighttime and daytime measurements, with a peak iATB of $\sim 0.03 \mathrm{sr}^{-1}$ in both cases. Given that there is relatively little difference in the backscatter from cirrus clouds between 532 and $1064 \mathrm{~nm}$ (Vaughan et al., 2010; Haarig et al., 2016), one would expect that the daytime and nighttime iATB distributions from $1064 \mathrm{~nm}$ retrievals should also be similar.

The daytime calibration coefficient is computed as

$C_{\text {day }}=\frac{1}{N_{\text {day }}} \sum_{k=1}^{N_{\text {day }}} \operatorname{iNRB}_{k} / \frac{1}{N_{\text {night }}} \sum_{k=1}^{N_{\text {night }}} \operatorname{iATB}_{k}$,

where both the nighttime iATB and daytime iNRB were computed over each calendar month of CATS data. The left panel of Fig. 4 demonstrates the CATS daytime calibration for the month of August 2016. In the CATS V2-01 data, the daytime cirrus iATB distribution is shifted higher than the nighttime distribution, with a peak at $0.05 \mathrm{sr}^{-1}$. For the V3-00 CATS processing, the daytime calibration coefficient for $\mathrm{Au}-$ gust 2016 was increased from $6 \times 10^{8}$ to $9 \times 10^{8} \mathrm{~km}^{3} \mathrm{sr} \mathrm{J}^{-1}$ counts and was applied to all August 2016 daytime granules. As seen in the right panel of Fig. 4, this change resulted in the peak of the daytime cirrus iATB distribution moving to $\sim 0.03 \mathrm{~km}^{-1} \mathrm{sr}^{-1}$ with better agreement with the nighttime distribution. Overall, it was found that a change of $\sim 1 \times 10^{8} \mathrm{~km}^{3} \mathrm{sr} \mathrm{J}^{-1}$ counts in the calibration coefficient results in a shift of $\sim 0.01 \mathrm{sr}^{-1}$ in the iATB. This method was applied to all CATS mode 7.2 daytime data in V3-00 on a monthly basis. Changes in the nighttime cirrus iATB distributions between versions are attributed to improvements in the layer type classifications within the $\mathrm{L} 2$ processing (Yorks et al., 2019).

Since the CATS daytime calibration coefficient is directly related to the nighttime calibration coefficient, the evolution of the daytime calibration coefficients is also correlated to the thermal stability of the cooling loop on the ISS (red dots, Fig. 3). Most of the CATS daytime calibration coefficients 

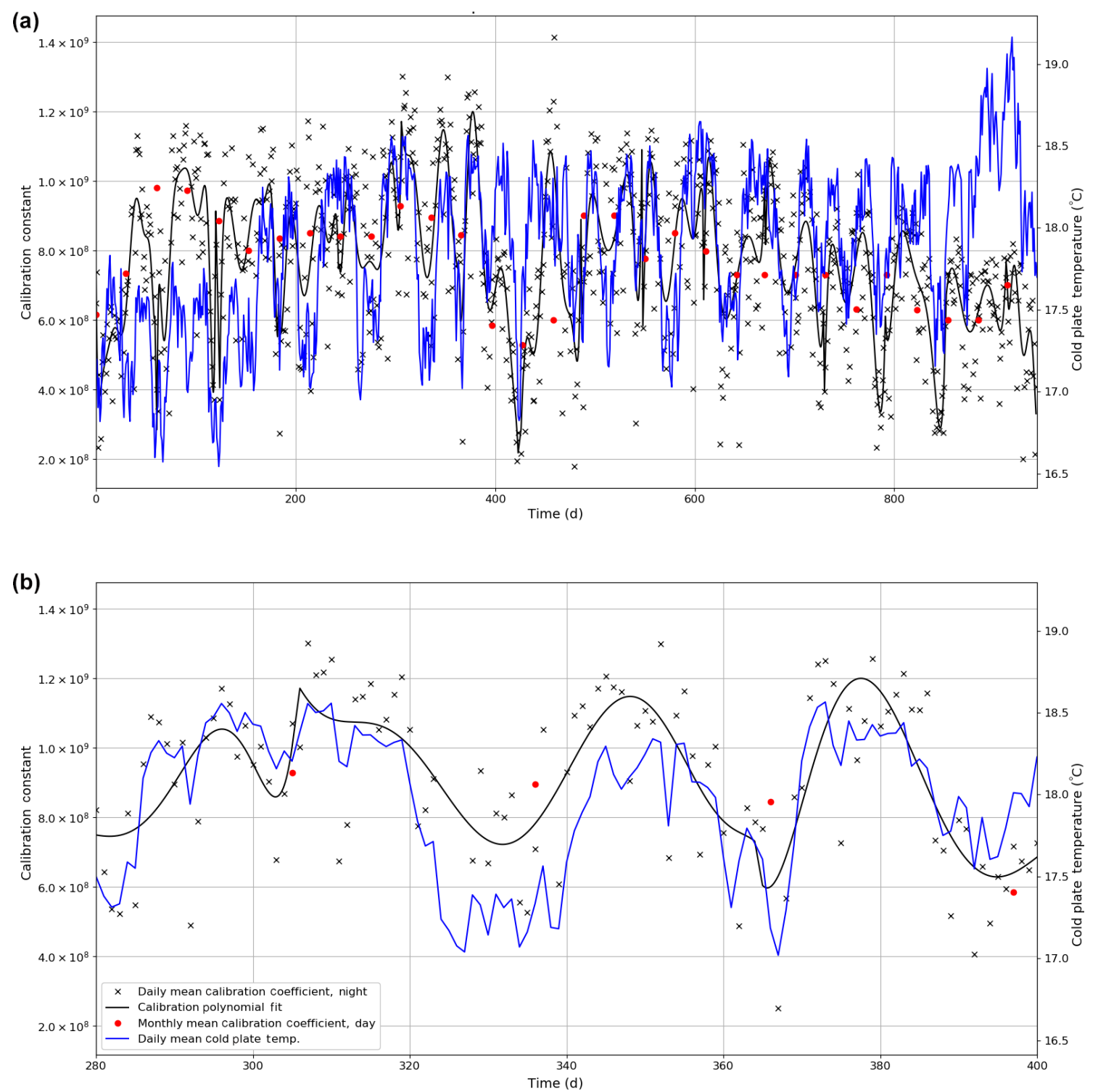

Figure 3. The average CATS nighttime calibration coefficient for each day (black x), polynomial fit of the average calibration coefficient with time (black line), the CATS monthly daytime calibration coefficient (red circle), and the daily average cold plate temperature (blue line) for the entire mode 7.2 data record (April 2015 through October 2017) in (a). Zooming into a smaller time period (January 2016 through April 2016, b) demonstrates the correlation between calibration values and the instrument cold plate temperature. The correlation coefficient between the daily average nighttime calibration coefficient and cold plate temperature for the January-April 2016 period is 0.8066 .

range from $6 \times 10^{8}$ to $9.0 \times 10^{8} \mathrm{~km}^{3} \mathrm{sr} \mathrm{J}^{-1}$ counts, with less variability compared to the nighttime calibration values given they are monthly-mean values (less temporal resolution than the nighttime values since it is computed every month and not every granule). The loss of this temporal resolution of the daytime calibration coefficients introduces a bias compared to the nighttime calibration coefficients. Overall, the daytime calibration method results in average biases of roughly $10 \%$, based on the mean, median, and mode daytime iATB values with respect to nighttime of $0.000168,-001215$, and $-0.00258 \mathrm{sr}^{-1}$, respectively (Table 1 ). The mean absolute er- ror (MAE) values also indicate that, overall, the distribution statistics between night and day granules are similar, with MAE values equating to $8 \%-13 \%$ error in the peak of the distribution and $17 \%$ error in the standard deviation of the distribution.

\section{Error analysis}

There are two types of error that contribute to the uncertainty in the CATS calibration: systematic and random errors. There are four sources of uncertainty included in the systematic er- 

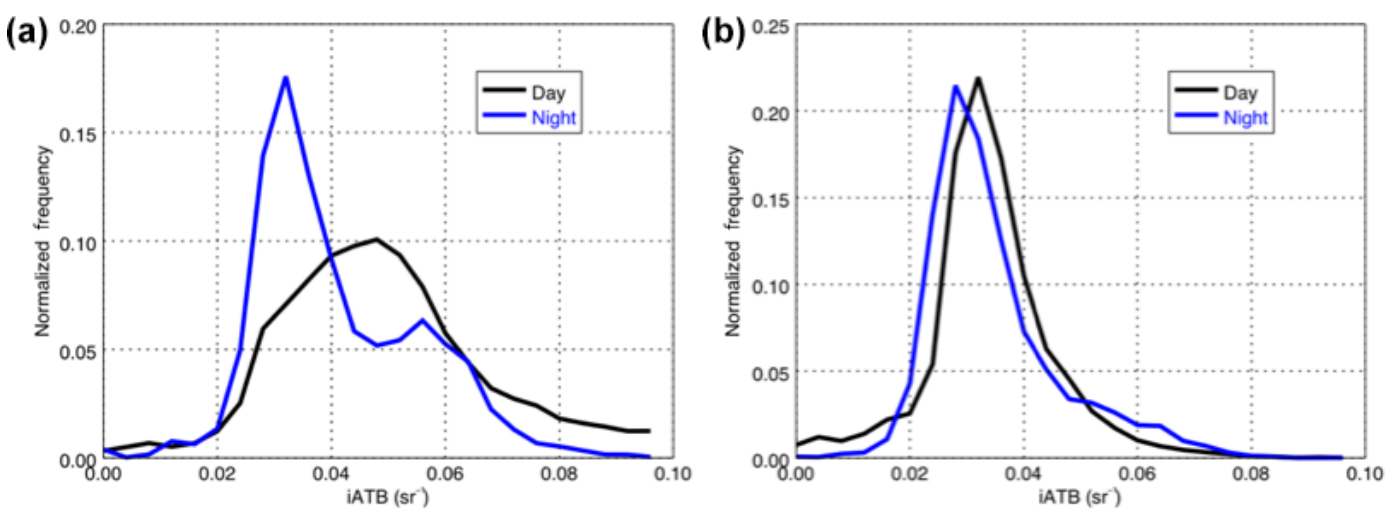

Figure 4. Distributions of CATS strongly scattering, rapidly attenuating opaque cirrus iATB distributions from V2-01 (a) and V3-00 (b). These plots demonstrate the CATS daytime calibration method using calibration transfer from the nighttime calibration.

ror calculation (Yorks et al., 2015). They are the following: uncertainties in the scattering ratios $(R)$ at $22-26 \mathrm{~km}$ from CALIOP, including assumptions of backscatter color ratio; uncertainties in the molecular backscatter $\left(\beta_{\mathrm{M}}\right)$ computed from MERRA-2 data; uncertainty in the modeled two-way transmittance $\left(T^{2}\right)$ from atmospheric molecules and ozone; and errors introduced by the CATS optical system. The optical system error can be reduced through corrections such as dead time correction and energy normalization to less than $0.1 \%$ and is therefore negligible. The total systematic error in the calibration, following the method outlined by Powell et al. (2009), can be defined as

$$
\begin{aligned}
& \left(\frac{\Delta C}{C}\right)_{\text {sys }}= \\
& \sqrt{\left(\frac{\Delta R}{R}\right)^{2}+\left(\frac{\Delta \beta_{\mathrm{M}}}{\beta_{\mathrm{M}}}\right)^{2}+\left(\frac{\Delta T_{\mathrm{M}}^{2}}{T_{\mathrm{M}}^{2}}\right)^{2}+\left(\frac{\Delta \chi_{\mathrm{p}}}{\chi_{\mathrm{p}}}\right)^{2}} .
\end{aligned}
$$

The errors in the molecular backscatter and background transmission are assumed to be constant, equaling $3 \%$ and $0.2 \%$ respectively. Regan et al. (2002) estimates transmission uncertainty for the $532 \mathrm{~nm}$ molecular backscatter coefficient of $3 \%$ and uncertainty at $1064 \mathrm{~nm}$ at a nominal cirrus cloud top altitude of $0.2 \%$. Thus, the constant $3 \%$ molecular backscatter uncertainty is conservative and results from uncertainties in GMAO-derived temperatures from the upper troposphere that are estimated to be less than $1{ }^{\circ} \mathrm{C}$ (Campbell et al., 2015). Omitting the King factor, which accounts for the anisotropy of molecules, in our molecular backscatter computation leads to an additional error of $1 \%-3 \%$ in the molecular backscatter error (Hostetler et al., 2005). This additional error contributes to less than $1 \%$ error in the total systematic calibration, making is far less important than other factors covered in this paper, especially given that the $1064 \mathrm{~nm}$ molecular backscatter uncertainty is likely overestimated. The error in the scattering ratio is dominated by the uncertainty and variability of the CALIOP nighttime scattering ratios, which ultimately results from the uncertainty in the CALIOP nighttime calibration, estimated to be $1.6 \% \pm 2.4$ (Kar et al., 2018). The final source of systematic error is the assumption that the backscatter color ratio of the stratospheric aerosols between 22 and $26 \mathrm{~km}$ is constant at 0.40 . To the authors' knowledge, the variability of the stratospheric aerosol backscatter color ratio is not documented in the literature, but an analysis of the Stratospheric Aerosol and Gas Experiment (SAGE) III extinctionÅngström exponent averaged from June 2017 to August 2018 in the CATS calibration region yields $1.79 \pm 0.10$. Thus, we assume an absolute uncertainty in the stratospheric aerosol backscatter color ratio of 0.024. Applying Eq. (8) to these values, the total systematic relative uncertainty in the CATS calibration coefficients is estimated at $7 \%$.

The random error in the CATS calibration is primarily caused by noise in the lidar signal during the calibration normalization. The random error can be determined through the variability of the NRB signal within each calibration segment (Welton and Campbell, 2002) and is calculated through

$$
\left(\frac{\Delta C}{C}\right)_{\mathrm{ran}}^{2}=\left(\frac{\left(\frac{\mathrm{SD}(\mathrm{NRB}(r))}{\sqrt{N}}\right)}{\mathrm{NRB}(r)}\right)^{2}
$$

where $N$ is the total number of NRB values used. For CATS, the 7.8 min averaging interval equals 9360 profiles. This averaging interval was chosen because it reduced the random error of each individual calibration value within a granule but still provided sufficient values (at least six) to compute the granule mean calibration coefficient. Uncertainties in background subtraction and other CATS correction terms (discussed in Sect. 2) are included in the NRB variability. The mean random error in the calibration coefficient is $6 \%$. The total error is determined through

$$
\left(\frac{\Delta C}{C}\right)_{\text {tot }}^{2}=\left(\frac{\Delta C}{C}\right)_{\mathrm{sys}}^{2}+\left(\frac{\Delta C}{C}\right)_{\mathrm{ran}}^{2}
$$


Table 1. Mean, median, mode, and standard deviation of the day and night iATB distributions of rapidly attenuating, opaque cirrus clouds from all V3-00 CATS data. The mean bias and mean absolute error (MAE) were also calculated between the day and night distributions.

\begin{tabular}{lrrrr}
\hline Night & Day & $\begin{array}{r}\text { Mean bias } \\
\text { (Night-day) }\end{array}$ & MAE \\
\hline Mean & $0.03840 \mathrm{sr}^{-1}$ & $0.03823 \mathrm{sr}^{-1}$ & $0.000168 \mathrm{sr}^{-1}$ & $0.003419 \mathrm{sr}^{-1}$ \\
Median & $0.03559 \mathrm{sr}^{-1}$ & $0.03681 \mathrm{sr}^{-1}$ & $-0.001215 \mathrm{sr}^{-1}$ & $0.003289 \mathrm{sr}^{-1}$ \\
SD & $0.01386 \mathrm{sr}^{-1}$ & $0.01390 \mathrm{sr}^{-1}$ & $-3.969 \mathrm{e}^{-5} \mathrm{sr}^{-1}$ & $0.002430 \mathrm{sr}^{-1}$ \\
Mode & $0.02981 \mathrm{sr}^{-1}$ & $0.03239 \mathrm{sr}^{-1}$ & $-0.00258 \mathrm{sr}^{-1}$ & $0.00413 \mathrm{sr}^{-1}$ \\
\hline
\end{tabular}

and thus comes to a total relative uncertainty in the CATS nighttime calibration $(\Delta C / C)$ of $\sim 9 \%$.

The daytime calibration uncertainty can be estimated from the variability of the NRB signal and the nighttime calibration error. The nighttime calibration already contains several systematic uncertainties that are inherited during the calculation of the daytime calibration coefficients. Additionally, since strongly scattering cirrus clouds are used in the daytime calibration, uncertainties in the multiple scattering factor, $\eta$, should also be considered. Multiple scattering occurs when laser light emitted by the lidar interacts with more than a single particle within a scattering volume. Multiple scattering can lead to higher detected signals and is corrected using the appropriate value of $\eta$ (Platt, 1979; Garnier et al., 2015). For CATS, $\eta$ for cirrus clouds was determined to be 0.52 through comparisons with the Cloud Physics Lidar (CPL). The magnitude of multiple scattering contributions to the backscattered signal depends critically on both instrument viewing geometry and particle phase function. However, since neither of these factors is expected to show any discernable diurnal variability, we assume that uncertainties in our knowledge of $\eta$ can be neglected when assessing the error sources for the CATS daytime calibration. Since a constant daytime calibration coefficient is determined for each month of CATS data and is based on comparisons with nighttime data, the total systematic error for the daytime calibration can be estimated to be the same as the average nighttime calibration uncertainty over the month.

The daytime random error is estimated from the variability in the NRB signal. Therefore, the total daytime error can be shown through the equation

$$
\begin{aligned}
& \left(\frac{\Delta C}{C}\right)_{\text {day }}^{2}=\left(\frac{1}{N_{\text {day }}}\right)^{2} \sum_{k=1}^{N_{\text {day }}}(\Delta \mathrm{iNRB})_{\text {day }, k}^{2} \\
& +\left(\frac{1}{N_{\text {night }}}\right)^{2} \sum_{k=1}^{N_{\text {night }}}(\Delta \mathrm{iNRB})_{\text {night }, k}^{2} \\
& +\frac{1}{N_{\text {night }}} \sum_{k=1}^{N_{\text {night }}}(\Delta C)_{\text {night }, k}^{2} .
\end{aligned}
$$

The daytime random error due to the noise in the NRB is estimated to be $\sim 15 \%$, leading to a total daytime calibration uncertainty of $\sim 16 \%-18 \%$.
The ATB uncertainties are computed using a propagation of errors from the NRB uncertainties. ATB is calculated through

$\mathrm{ATB}=\frac{\mathrm{NRB}}{C}$.

NRB uncertainties ( $\triangle \mathrm{NRB}$ ) are calculated using the methodology outlined in Welton and Campbell (2002). By utilizing a standard propagation of errors from the NRB uncertainty and the calibration uncertainty, the ATB uncertainty was computed and can be expressed as

$\Delta \mathrm{ATB}=\sqrt{\left(\frac{1}{C}\right)^{2} \Delta \mathrm{NRB}^{2}+\Delta C^{2}\left(\frac{\mathrm{NRB}}{C^{2}}\right)^{2}}$.

As part of the NRB error, there is error associated with the molecular folding correction factor (see Sect. 2.1) which impacts the ATB profile. Since the correction factor acts by matching the slope of the measured signal to that of the modeled molecular profile within the calibration region, the error was assessed through the amount of error introduced lower in the CATS profile for given errors in the calibration region slope. In V3-00, the majority of corrected slopes in the calibration region have an error of less than $3.5 \%$. However, in very few cases, the slope is different from the molecular slope by $10 \%$ in the calibration region. The assessment of this worst-case calibration region slope error showed that the maximum error introduced in the profile is $\sim 4 \%$ in the 17 $18 \mathrm{~km}$ region. The error in the profile then decreases as the signal approaches the surface, introducing $\sim 2 \%$ error.

The CATS $1064 \mathrm{~nm}$ ATB uncertainties for clouds and aerosols at night are primarily a related to the uncertainties in the atmospheric normalization technique. Features such as cloud and aerosol layers with higher backscatter intensities tend to have lower ATB uncertainty, while clear-air regions, with lower scattering intensity and lower SNR, have higher ATB uncertainty. The median CATS $1064 \mathrm{~nm}$ ATB relative uncertainties from the mode 7.2 V3-00 data products within cloud and aerosol layers are $7 \%$ at night and $21 \%$ during daytime. For clear-air regions, there is large variability ( $20 \%$ to over $100 \%$ ) in the CATS $1064 \mathrm{~nm}$ ATB relative uncertainties, since the SNR varies as a function of altitude at night due to molecular scattering and scene during daytime due to the noise introduced from the solar background. 


\section{Data comparisons}

\subsection{Airborne lidar comparisons}

During the CATS-CALIOP Airborne Validation Experiment (CCAVE) in August 2015, the NASA ER-2 conducted several ISS underflights. As part of the CCAVE payload, CPL was able to collect coincident data with CATS. CPL is an airborne backscatter lidar that has participated in over thirty field campaigns, including several satellite instrument validation projects (McGill et al., 2002). CPL data products include ATB from both 1064 and $532 \mathrm{~nm}$. Similar to nighttime CATS data, CPL is calibrated by normalizing the signals acquired between 15 and $17 \mathrm{~km}$ to a modeled molecular attenuated backscatter profile derived from MERRA-2 reanalysis data. A $1064 \mathrm{~nm}$ particulate scattering ratio of 1.27 is applied in the calibration region for $1064 \mathrm{~nm}$ data, based on the work of Vaughan et al. (2010), and the estimated aerosol loading within a standard atmospheric profile in the Northern Hemisphere.

Figure 5 shows the coincident flight from the CCAVE project which occurred at 01:37 UTC on 7-8 August 2015 during the day over western Nevada. CPL flew beneath CATS with clear-sky conditions, although this scene is made more complicated due to variations in the terrain and background smoke aerosols due to wildfires in the region, as can be seen in the curtain plot (Fig. 5a). The CATS average is comprised of 165 profiles which span $55 \mathrm{~km}$ and is calibrated using the daytime cirrus cloud calibration transfer technique. The CPL mean profile is an average of 280 profiles. Despite the complicated terrain and smoke, the mean ATB profiles from CATS and CPL still shows good agreement in the clear-sky region above the smoke, with the average CPL and CATS mean ATB between 7 and $15 \mathrm{~km}$ equal to $4.1927 \times 10^{-5}$ and $4.0972 \times 10^{-5} \mathrm{~km}^{-1} \mathrm{sr}^{-1}$ respectively, meaning the CATS average ATB was $2.28 \%$ below CPL. This agreement is surprising since the CATS daytime calibration uncertainty is $\sim 16 \%-18 \%$, but this case occurred near local twilight when CATS SNR is higher and the 1.27 value of the $1064 \mathrm{~nm}$ particulate scattering ratio used for CPL could be too low, introducing errors in the CPL $1064 \mathrm{~nm}$ ATB profile.

Another daytime underpass occurred at 20:31 UTC on 20 August 2015 over northern Utah near the Great Salt Lake. The CPL curtain plot and the mean ATB profile from both CATS and CPL centered around the overpass time can be seen in Fig. 6. The CPL data were averaged to $6 \mathrm{~min}(360$ ATB profiles), which covers a distance of about $70 \mathrm{~km}$. The CATS data were averaged over the same distance and are comprised of 210 ATB profiles, and like the 7-8 August 2015 case they are calibrated using the daytime cirrus cloud calibration transfer technique. As shown in the CPL curtain plot, the underpass segment was in clear-sky conditions (no clouds) with a well-defined smoke aerosol layer from nearby wildfires. Both instruments observed the top of this aerosol layer around $5 \mathrm{~km}$ a.m.s.l. The differences in SNR are also apparent as the CATS profile is noisier than the CPL profile. The average CPL ATB value between 7 and $15 \mathrm{~km}$ was $4.2967 \times 10^{-5} \mathrm{~km}^{-1} \mathrm{sr}^{-1}$ and the average CATS ATB was $5.1939 \times 10^{-5} \mathrm{~km}^{-1} \mathrm{sr}^{-1}$, which is $20.88 \%$ higher than CPL. These differences are expected given the 16\%-18\% CATS daytime calibration uncertainty.

The greater noise in the CATS signal on the 20 August case should be noted as compared to the 7-8 August case. This is likely attributed to the different times of day the two flights occurred. The 7-8 August flight occurred in the early evening, which will minimize the noise induced by solar background due to the lower sun angles, while the $20 \mathrm{Au}$ gust flight occurred closer to local noon, which will maximize noise from sunlight. For both underflights, the error in the CATS ATB compared with CPL is well within the uncertainty estimates of both instruments.

\subsection{Ground-based comparisons}

In addition to the coincident airborne CPL data, CATS was also compared to ground-based systems. CATS frequently passed over (or close to) the European Aerosol Research Lidar Network (EARLINET) sites. The Polly ${ }^{\mathrm{XT}}$ lidar (Baars et al., 2016; Engelmann et al., 2016) is a Raman lidar developed by the Leibniz Institute for Tropospheric Research (TROPOS), Leipzig, Germany, and is used at some EARLINET sites. The Polly ${ }^{\mathrm{XT}}$ systems emit laser pulses at 1064, 532, and $355 \mathrm{~nm}$ with elastic backscatter detectors at each wavelength, as well as Raman channel detectors at 386.73 and $607.4 \mathrm{~nm}$. There are Polly ${ }^{\mathrm{XT}}$ lidars all across Europe as part of the EARLINET, but only data collected from the Leipzig, Germany $\left(51.3^{\circ} \mathrm{N} ; 12.4^{\circ} \mathrm{E}\right)$, and the Athens NOA (National Observatory of Athens) $\left(37.97^{\circ} \mathrm{N} ; 23.71^{\circ} \mathrm{E}\right)$ sites were used in this study.

Raw EARLINET data are processed through the Single Calculus Chain (SCC) (D'Amico et al., 2015). The first part of the SCC is the EARLINET Lidar Pre-Processor (ELPP) where the raw lidar signal is range and dead time corrected, the background signal is subtracted, and molecular extinction and transmission profiles are computed from meteorological radiosonde data or the standard atmosphere (D'Amico et al., 2016). The second part of the SCC is the EARLINET Lidar Data Analyzer (ELDA) (Mattis et al., 2016). In the ELDA the backscatter coefficients, extinction coefficients, and lidar ratio are derived. During the backscatter coefficient calculation, the EARLINET data are calibrated by normalizing it to the molecular signal using an assumed aerosol-free region, which is determined by the ELDA algorithms.

Using the particulate backscatter and particulate extinction profiles derived from the Polly ${ }^{\mathrm{XT}}$ data, CATS-like ATB profiles were calculated following the methodology outlined in Mona et al. (2009), where the attenuated backscatter coefficient can be defined as

$\beta^{\prime}(z)=\beta_{\mathrm{tot}}(z) T_{\mathrm{par}}^{2}(z) T_{\mathrm{M}}^{2}(z)$. 

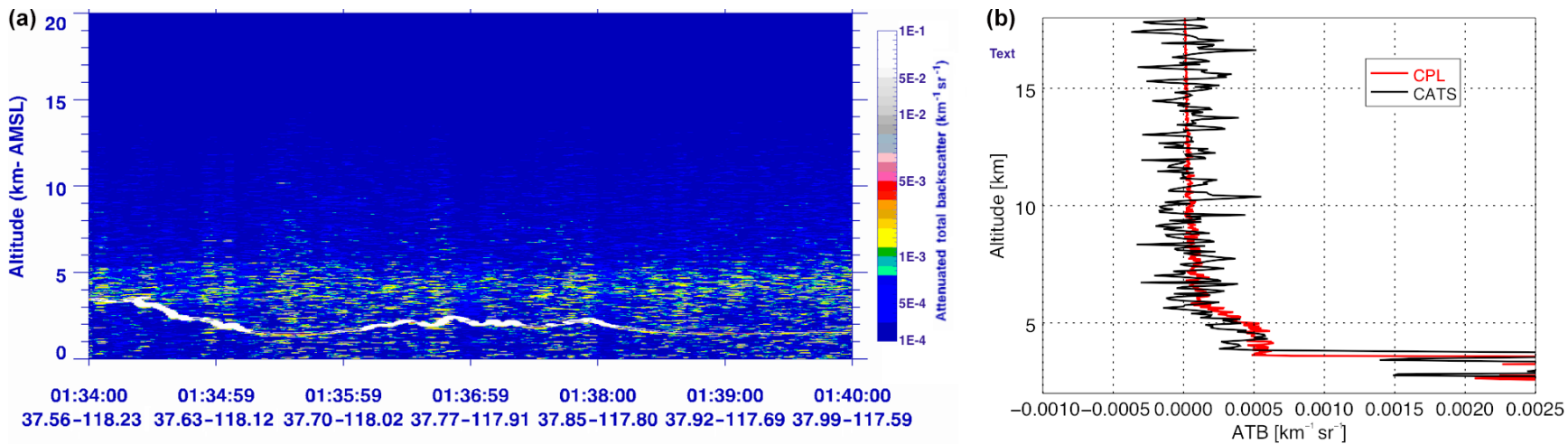

Figure 5. The CPL curtain plot of ATB centered around the 01:37 UTC coincident point from the 7 to 8 August 2015 CCAVE flight (a). The mean ATB profiles from CATS and CPL during this underflight (b).
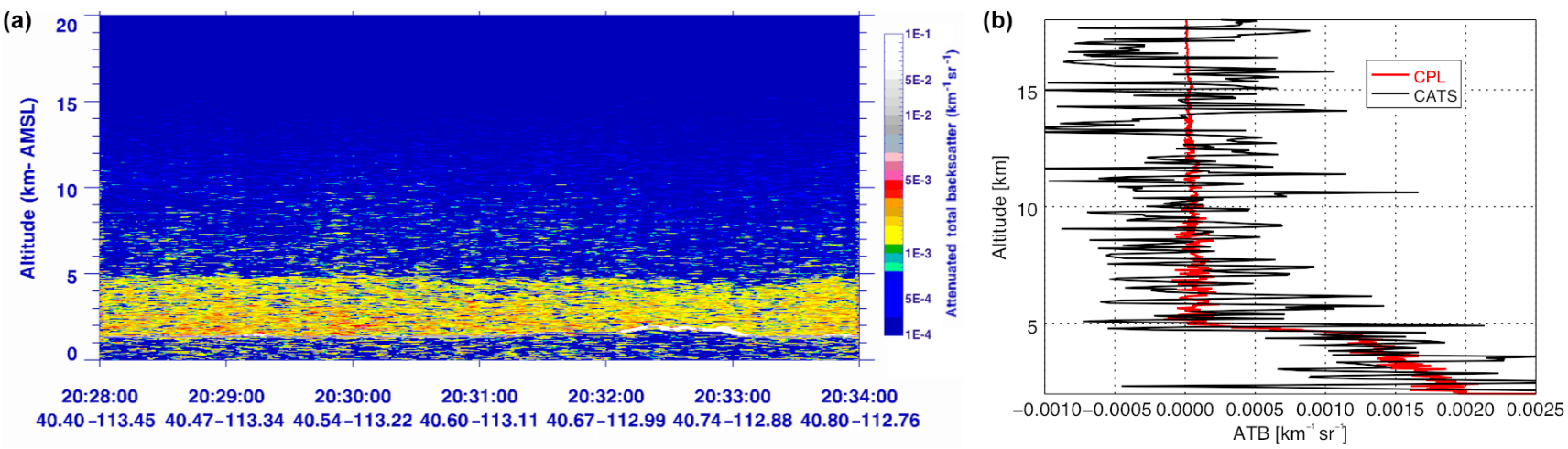

Figure 6. The 20 August 2015 CATS/CPL coincident flight. The CPL $70 \mathrm{~km}$ coincident segment curtain plot (a) was used to compute the mean ATB profile (b) from CPL along the same path as CATS. The CATS and CPL data show good agreement despite higher noise levels in the CATS profile due to daytime retrieval limitations.

$\beta_{\text {tot }}$ is the total backscatter coefficient comprised of contributions from particles, molecules, and ozone. $T_{\text {par }}^{2}$ is the particulate transmittance and is calculated through

$T_{\text {par }}^{2}(z)=\exp \left(-2 \int_{z}^{z_{\mathrm{s}}} \alpha_{\mathrm{par}}(\zeta) \mathrm{d} \zeta\right)$

where $\alpha_{\text {par }}$ is the particulate extinction and $z_{\mathrm{s}}$ is the CATS altitude. The particulate backscatter was computed from the Polly XT 1064 and $607 \mathrm{~nm}$ signals through the methodology described in Proestakis et al. (2019). The uncertainty in the backscatter coefficient retrieval is estimated to be between $5 \%$ and $20 \%$ (Ansmann et al., 1992; Whiteman et al., 2003; Povey et al., 2014). The particulate extinction coefficient was calculated using the Klett method (Klett, 1981; Fernald, 1984) using assumed lidar ratios between 30 and 35 sr. Sun photometer data were used, wherever possible, to estimate the lidar ratio. The molecular signal and attenuation profiles were computed from the temperature and pressure profiles found within the CATS L1B HDF5 file corresponding to the overpass.
Figure 7 shows the mean ATB profiles from the nighttime CATS overpass of the Leipzig Polly ${ }^{X T}$ site on 24 September 2015 at 01:13:34 UTC. CATS passed $31 \mathrm{~km}$ from the Leipzig site. The mean profiles consist of 40 CATS ATB profiles ( $\sim 10 \mathrm{~km})$ and 30 min of Polly ${ }^{\mathrm{XT}}$ data (36000 profiles). This difference in the number of averaged profiles is a contributing factor to the difference in the noise between the two instrument profiles. The CATS mean ATB profile was $7.7 \%$ higher than the Polly ${ }^{X T}$ mean CATS-like signal between 3 and $12 \mathrm{~km}$. Another nighttime overpass, shown in Fig. 8, occurred on 30 July 2015 at 00:18:19 UTC $\sim 41 \mathrm{~km}$ away from the Leipzig site. In this overpass, CATS ATB was $14.1 \%$ lower than the Polly ${ }^{\mathrm{XT}}$ data between 3 and $12 \mathrm{~km}$.

Overall, eight clear-sky, nighttime overpasses were used in this analysis. The average difference from 3 to $12 \mathrm{~km}$ between CATS and Polly XT ATB was $19.7 \%$ with an average CATS distance from the Polly ${ }^{X T}$ site of $40 \mathrm{~km}$ (Fig. 9). Figure 9 also shows the CATS and Polly XT ATB scatter plot from all eight overpasses. The correlation coefficient between the two instrument retrievals is 0.75 . The difference between the two instruments falls within the uncertainties in the CATS ATB (Sect. 3) and the uncertainties in the Polly XT 


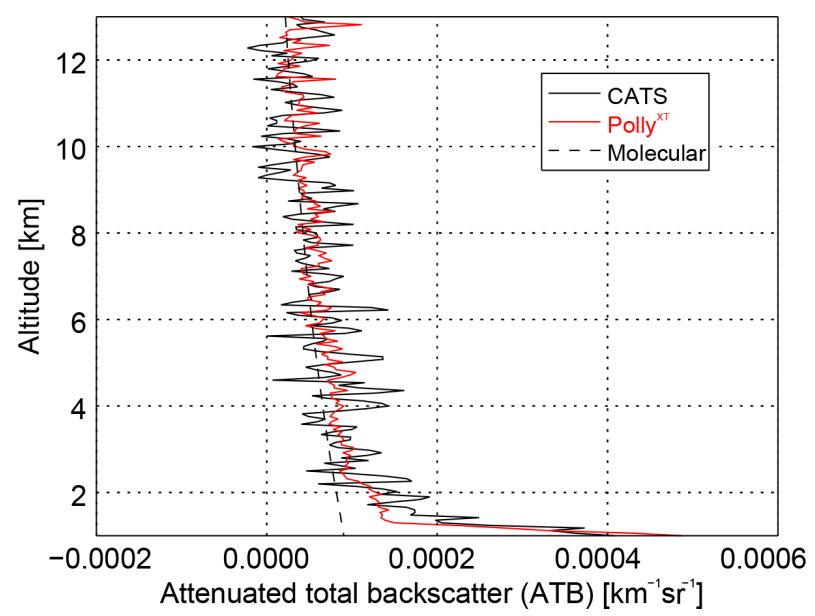

Figure 7. The mean CATS and Polly $\mathrm{XT}$ ATB profiles from the CATS overpass of the Leipzig, Germany, EARLINET site at 01:13:34 UTC on 24 September 2015. CATS passed within $31 \mathrm{~km}$ of the EARLINET site.

retrievals. In addition to the clear-sky comparisons, one overpass which had strong aerosol scattering within the planetary boundary layer (PBL) was assessed. The centermost $1.25 \mathrm{~km}$ of the PBL depth retrievals were compared to avoid spatial inhomogeneities in the PBL top and ground height. CATS underestimated Polly ${ }^{\mathrm{XT}}$ by $7 \%$, supporting the ATB uncertainty assessment in Sect. 3 of lower ATB uncertainties $(\sim 8 \%)$ within stronger backscattering layers. Given the high SNR of the CATS $1064 \mathrm{~nm}$ nighttime signal (Fig. 1), these differences can be primarily attributed to the $\sim 9 \%$ uncertainty in the CATS nighttime atmospheric normalization calibration technique.

Previous studies have investigated the validity of using EARLINET for spaceborne lidar validation (Mamouri et al., 2009; Papagiannopoulos et al., 2016; Proestakis et al., 2019) and have found it is a useful method for lidar validation. A major source of the variability between the ground-based and spaceborne measurement results was found to be the variances in the atmospheric scene observed due to the spatial and temporal differences in the measurements. In a CALIOP validation study by Mamouri et al. (2009), it was found that for comparisons where the over pass was within $100 \mathrm{~km}$ from the EARLINET site the variability of the aerosol loading introduced a discrepancy on the order of $5 \%$.

\subsection{CALIOP comparison}

In addition to coincident data, statistical comparisons with CALIOP measurements can be used to further assess the CATS calibration. However, differences in instrument design can make the interpretation of these comparisons somewhat challenging. CALIOP measures the total backscatter in the $1064 \mathrm{~nm}$ channel using a single avalanche photodiode (APD), which simultaneously delivers a desirable high quan-

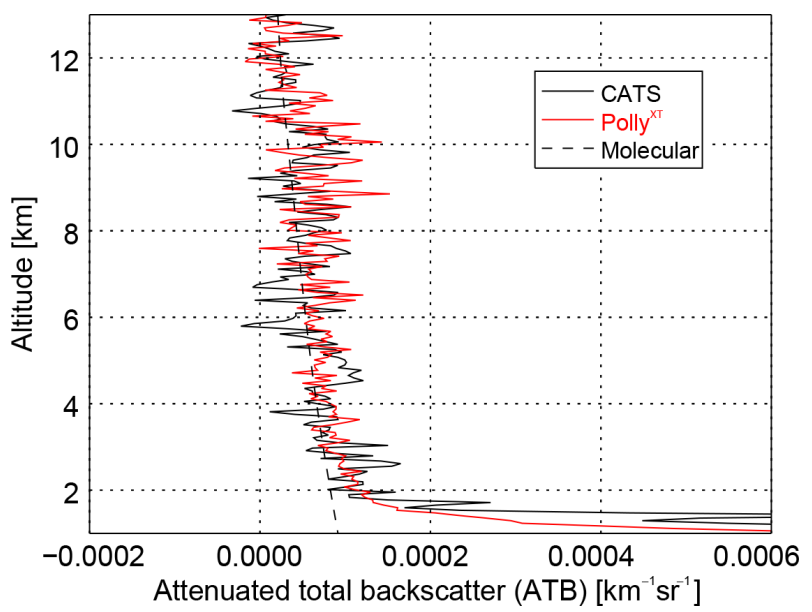

Figure 8. The mean CATS and Polly ${ }^{X T}$ ATB profiles from the CATS overpass of the Leipzig, Germany, EARLINET site at 00:18:19 UTC on 30 July 2015. CATS passed within $41 \mathrm{~km}$ of the EARLINET site.

tum efficiency and a less desirable high dark noise count rate that has been increasing linearly over the course of the mission (Hunt et al., 2009). CATS, on the other hand, uses a pair of photon-counting modules to separately measure the $1064 \mathrm{~nm}$ backscatter components polarized parallel and perpendicular to the polarization plane of the CATS laser. The difference in detector performance is illustrated in Fig. 10, which shows the occurrence frequencies of the attenuated backscatter coefficients measured by CATS and CALIOP between 1 April and 30 September 2016 at all latitudes between $51.8^{\circ} \mathrm{N}$ and $51.8^{\circ} \mathrm{S}$. This comparison was designed to investigate distributions of cirrus cloud backscatter intensity, so the data are restricted to nighttime measurements extending from 0 to $5 \mathrm{~km}$ above the point where the atmospheric temperature in any profile first drops below $-40{ }^{\circ} \mathrm{C}$.

Because CATS uses photon-counting detectors, the molecular backscatter signals in the CATS distribution appear as a sharp, well-confined peak at $\sim 2.5 \times 10^{-5} \mathrm{~km}^{-1} \mathrm{sr}^{-1}$. The substantial broadening of the CALIOP distribution in this region is a consequence of the high APD dark noise levels in the CALIOP detectors. The distributions begin to converge above $\sim 0.008 \mathrm{~km}^{-1} \mathrm{sr}^{-1}$, although the CATS occurrence frequencies remain persistently lower than CALIOP throughout. Approximately $99.7 \%$ of all attenuated backscatter coefficients measured for both lidars lie below $0.025 \mathrm{~km}^{-1} \mathrm{sr}^{-1}$. Some of the differences at higher ATB values may be a consequence of the fact that these are not coincident measurements; because the two instruments fly in very different orbits, they sample different regions of the atmosphere at different times of day. CALIPSO flies in a sun-synchronous $98^{\circ}$ orbit with a $16 \mathrm{~d}$ repeat time, and thus CALIOP measurements are acquired at approximately the same time of day at any given location along the orbit track (Hunt et al., 2009). The ISS flies in a $52^{\circ}$ precessing orbit with a $3 \mathrm{~d}$ repeat time, 

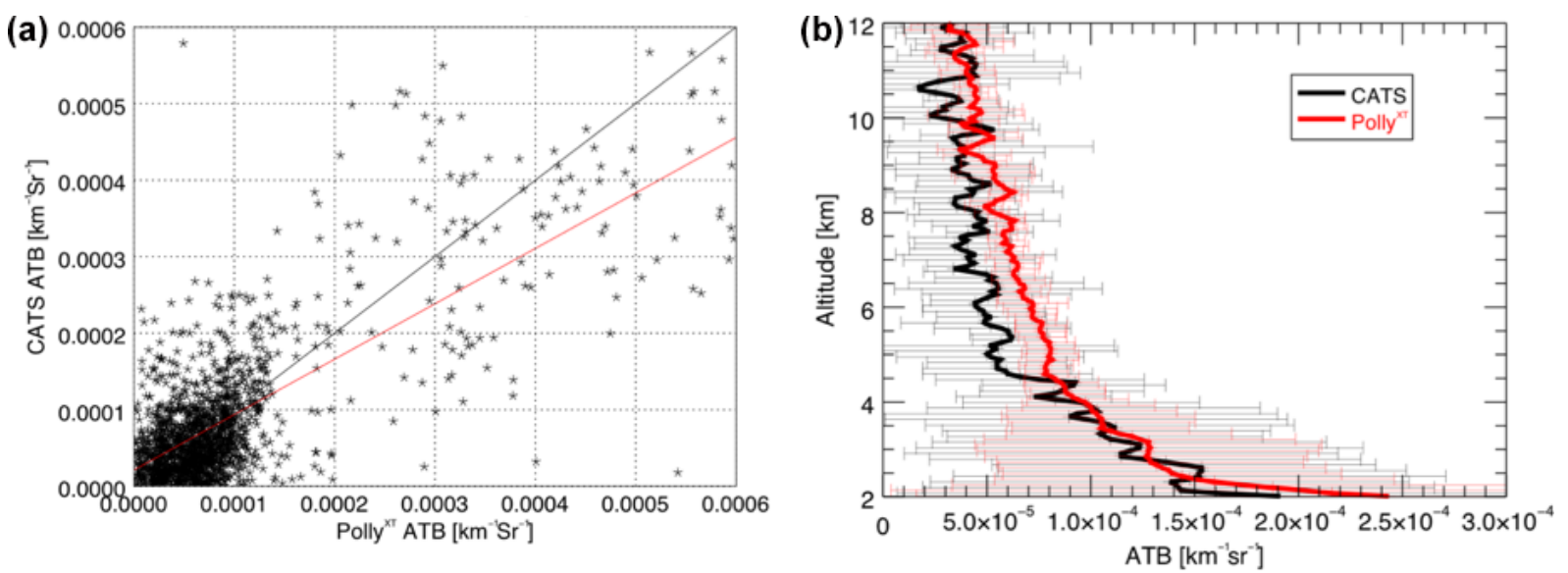

Figure 9. Scatter plot of all eight Polly ${ }^{X T}$ CATS comparison overflights (a). The black line is the one-to-one line while the red line is the line fit of the data set. The correlation coefficient is 0.75 . The average ATB profile from all eight Polly XT_CATS comparison cases (b) shows the CATS mean profile is on average $19.67 \%$ lower than Polly ${ }^{\mathrm{XT}}$ from 3 to $12 \mathrm{~km}$. The horizontal lines show the standard deviations of the mean profile for both CATS and Polly $\mathrm{XT}$.

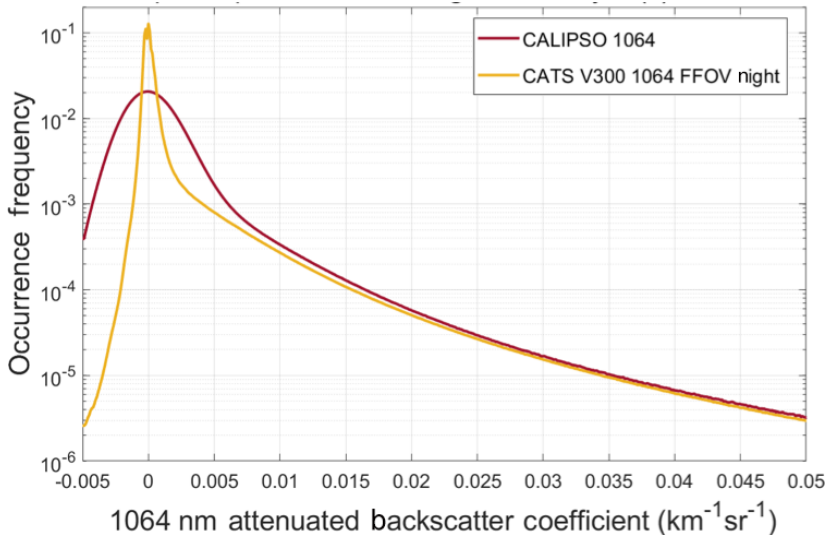

Figure 10. Relative frequency distributions of $1064 \mathrm{~nm}$ attenuated backscatter coefficients measured by CALIOP (V4.10) and CATS (V3-00) from April through September 2016 at night with temperatures less than $-40^{\circ} \mathrm{C}$.

so that CATS measurements at identical locations will occur at many different times of the day. This precessing orbit allows CATS data to be used to assess the diurnal variability of clouds and aerosols.

To avoid the confounding effects introduced by APD dark noise contamination of the weaker signals measured by CALIOP, a second study was conducted comparing the iATB from opaque cirrus detected by the two sensors. This study used CATS and CALIOP data acquired between 1 March and 31 December 2016, with the latitude range once again confined to between $51.8^{\circ} \mathrm{N}$ and $51.8^{\circ} \mathrm{S}$. The following cloud selection criteria were applied uniformly to both data sets.

a. All layers must be classified as opaque ice clouds and be the uppermost (and only) layer in the column. b. All layers must be detected at a nominal $5 \mathrm{~km}$ horizontal averaging resolution.

c. The midlayer temperature for all layers must lie below $-37^{\circ} \mathrm{C}$ (see Campbell et al., 2015).

d. Only nighttime measurements are used.

A comparison of the resulting frequency distributions is shown in Fig. 11. Descriptive statistics of the iATB values measured by each lidar are given in Table 2 . In both Fig. 11 and Table 2, the mean CATS iATB is seen to underestimate CALIOP by $\sim 11.8 \%$. However, direct comparisons of mean iATB measured in opaque cirrus cannot fully characterize the calibration differences between the two instruments. In particular, any comprehensive evaluation must consider differences in the contributions of multiple scattering to the backscattered signals. Instrument-specific causes for these differences include different laser spot sizes, different receiver fields of view, and different orbit altitudes.

The iATB for opaque layers can be expressed in terms of the layer extinction-to-backscatter ratio, $S$ (more commonly known as the lidar ratio), and a dimensionless, instrumentspecific multiple scattering factor, $\eta$, using Platt's equation (Platt, 1973):

$\mathrm{iATB}=\frac{1}{2 \eta S}$.

Aggregating 10 months of nighttime measurements acquired within the same time frame and latitude limits yields very large sample sizes for both data sets, so we can reasonably assume that the distribution of lidar ratios observed by CATS and CALIOP are essentially identical. But we cannot assume that the CATS and CALIOP multiple scattering factors are identical, as they depend not only on the phase functions 


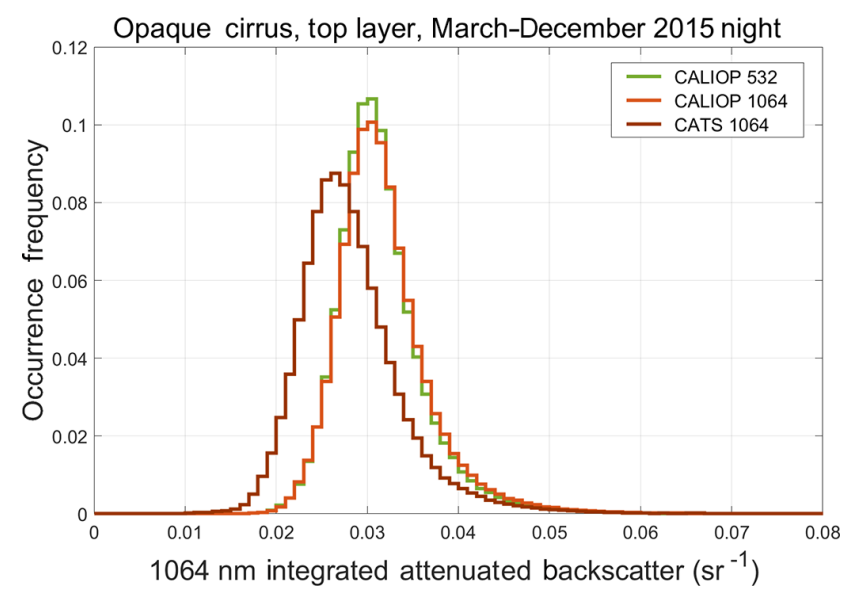

Figure 11. Relative frequency distributions of March-December 2015 nighttime integrated attenuated backscatter for opaque cirrus clouds measured by CALIOP at 532 and $1064 \mathrm{~nm}$ and by CATS at $1064 \mathrm{~nm}$ only.

of the measurement targets (in this case, cirrus clouds) but also on instrument design and viewing geometry (Winker, 2003). As mentioned in Sect. 3, the value of $\eta$ for CATS $\left(\eta_{\text {CATS }}=0.52\right)$ has been determined empirically via comparisons to coincident CPL measurements. The cirrus multiple scattering factors applied in the CALIOP V4.10 data release were also determined empirically using extensive coincident measurements made by the CALIPSO infrared imaging radiometer (Garnier et al., 2015). Unlike CATS, $\eta_{\text {CALIOP }}$ is not a fixed constant but is instead implemented as a function of cloud temperature.

For the opaque cirrus clouds sampled by CALIOP in this study, $\eta_{\text {CALIOP }}=0.55 \pm 0.06$. Assuming that both instrument teams have accurately characterized cirrus multiple scattering effects on their respective systems, enforcing the assumption that the lidar ratio distributions observed by CATS and CALIOP are essentially identical, we can establish the relative difference in attenuated backscatter measurements between the two lidars using (iATB ${ }_{\text {CALIOP }} \times$ $\left.\eta_{\text {CALIOP }}\right) /\left(\right.$ iATB $\left._{\text {CATS }} \times \eta_{\text {CATS }}\right)=(0.0313 \times 0.55) /(0.0280 \times$ $0.52)=1.182$. This result is consistent with the previous Polly ${ }^{\mathrm{XT}}$ comparisons. In clear-air regions, the difference between CATS V3-00 L1B data products and Polly ${ }^{\mathrm{XT}}$ measurements of ATB is $\sim 19.7 \%$. In opaque cirrus, differences between CATS V3-00 L1B data products and CALIOP measurements of iATB are $\sim 18.2 \%$.

\section{Conclusions}

This study presents the CATS $1064 \mathrm{~nm}$ calibration algorithm, as well as validation using three different data sources. Cloud and aerosol layers have strong backscatter intensities and high SNR, so the CATS $1064 \mathrm{~nm}$ ATB uncertainties in these layers are primarily related to the uncertainties in the CATS
Table 2. Descriptive statistics for the integrated attenuated backscatter of opaque cirrus clouds detected during nighttime granules by CATS and CALIOP during the period from 1 March to 31 December 2015 (MAD: median absolute distance).

\begin{tabular}{lrrr}
\hline & CALIOP 532 nm & CALIOP $1064 \mathrm{~nm}$ & CATS 1064 nm \\
\hline Minimum & $0.0017 \mathrm{sr}^{-1}$ & $0.0015 \mathrm{sr}^{-1}$ & $0.0001 \mathrm{sr}^{-1}$ \\
Maximum & $0.1189 \mathrm{sr}^{-1}$ & $0.1248 \mathrm{sr}^{-1}$ & $0.1794 \mathrm{sr}^{-1}$ \\
Median & $0.0303 \mathrm{sr}^{-1}$ & $0.0305 \mathrm{sr}^{-1}$ & $0.0270 \mathrm{sr}^{-1}$ \\
MAD & $0.0036 \mathrm{sr}^{-1}$ & $0.0038 \mathrm{sr}^{-1}$ & $0.0045 \mathrm{sr}^{-1}$ \\
Mean & $0.0310 \mathrm{sr}^{-1}$ & $0.0313 \mathrm{sr}^{-1}$ & $0.0280 \mathrm{sr}^{-1}$ \\
SD & $0.0050 \mathrm{sr}^{-1}$ & $0.0053 \mathrm{sr}^{-1}$ & $0.0071 \mathrm{sr}^{-1}$ \\
\hline Samples & 333228 & 333228 & 268806 \\
\hline
\end{tabular}

calibration. At night, CATS V3-00 median 1064 nm ATB relative uncertainty is $7 \%$ in cloud and aerosol layers, slightly lower than the estimated $\sim 9 \%$ uncertainty in the atmospheric normalization technique. The daytime cirrus cloud calibration transfer technique has an estimated uncertainty of 16\%-18\%. CATS V3-00 median daytime $1064 \mathrm{~nm}$ ATB relative uncertainty is $21 \%$ in cloud and aerosol layers. Coincident flights with the airborne CPL instrument showed that, even in conditions with peak solar background noise and lowest SNR, CATS data agree to within $25 \%$ with CPL. The CATS ATB was also compared with the ground-based EARLINET systems and found to be within $20 \%$ of the calibrated EARLINET data. Finally, CATS was compared in a statistical sense with CALIOP, another spaceborne lidar utilizing a different $1064 \mathrm{~nm}$ calibration method than CATS, and also found ATB agreement to $\sim 18 \%$. The comparisons between CATS, CPL, Polly ${ }^{\mathrm{XT}}$, and CALIOP $1064 \mathrm{~nm}$ ATB fall within the combined estimated uncertainties for all the instruments. The results shown in this paper are critical to understanding the uncertainties in CATS $1064 \mathrm{~nm}$ Level 2 data products, as the calibration uncertainties from backscatter lidars generally impose a lower bound on the uncertainties in cloud/aerosol extinction and optical depth retrievals from such instruments (Young et al., 2013, 2016). To date, the CATS cloud and aerosol top/base heights have been used for various applications, including volcanic plume transport (Hughes et al., 2016), above-cloud aerosol properties (Rajapakshe et al., 2017), pyrocumulonimbus smoke heights (Christian et al., 2019), and cloud diurnal variability (Noel et al., 2018). More recently, CATS cloud and aerosol optical properties (e.g., extinction, optical depth, ice water content) from Level $2 \mathrm{~V}$ 3.00 data have been compared to EARLINET aerosol products (Proestakis et al., 2019), used to estimate thin cirrus radiative forcing (Dolinar et al., 2019), and demonstrated the diurnal variability of aerosol properties (Lee et al., 2019).

CATS has demonstrated that direct calibration of $1064 \mathrm{~nm}$ from spaceborne lidar is possible given the appropriate instrument design and orbit. The CATS design and ISS orbit yielded data that exhibit high nighttime SNR, enabling the direct calibration of the nighttime CATS $1064 \mathrm{~nm}$ ATB 
by normalizing the signal to the Rayleigh profile corrected for aerosol contributions. The primary strength of this technique is that it does not require assumptions about cirrus cloud $1064-532 \mathrm{~nm}$ backscatter color ratios, as is the case with the CALIOP $1064 \mathrm{~nm}$ calibration technique (Vaughan et al., 2019). The accuracy of the atmospheric normalization technique, which is also used for CALIOP $532 \mathrm{~nm}$ data, is dependent on an accurate estimate of the aerosol loading in the calibration altitude region. A weakness of the CATS $1064 \mathrm{~nm}$ atmospheric normalization technique is that assumptions about the $1064-532 \mathrm{~nm}$ backscatter color ratio for stratospheric aerosols are used because accurate measurements of the $1064 \mathrm{~nm}$ aerosol loading in the $22-26 \mathrm{~km}$ altitude region, which has higher aerosol loading than the 36$39 \mathrm{~km}$ region used for CALIOP, were not available in same timeframe as CATS operations. To improve the calibration of future space-based lidar missions, especially at $1064 \mathrm{~nm}$, a higher calibration altitude region should be prioritized. This could be achieved by choosing a laser repetition rate of $4 \mathrm{kHz}$ (or lower) and setting a data frame of $37.5 \mathrm{~km}$ (or greater) to reduce the aerosol scattering ratio to $<1.10$. Also, coincident passive measurements of stratospheric aerosol backscatter or extinction at a similar wavelength should be considered. Implementing these into a mission design would likely reduce the nighttime calibration uncertainties by a factor of 2 , which would then improve the accuracy of the resulting layer information and aerosol/cloud optical properties derived from the calibrated signal. Accurate backscatter lidar data are critical to improve our understanding of various physical properties of the atmosphere, specifically how clouds and aerosols radiatively impact our Earth in the infrared.

Data availability. CATS data products are archived through the Atmospheric Science Data Center (ASDC). CATS browse images and data products are also freely distributed via the CATS website at https://cats.gsfc.nasa.gov/data/.

Author contributions. RP conducted the formal analysis, validation, and calibration of daytime data and wrote the manuscript. JY worked on the methodology of the study as well as conducted editing and revisions. DH developed the calibration algorithms for CATS. MM developed the CATS instrument and primarily acquired the funding for this study. VA, AG, and HB provided EARLINET data and contributed to the analysis of that data. SP developed the algorithms for the molecular folding correction and conducted error analysis on that correction. SR and MV conducted the analysis between CATS and CALIOP, provided visualizations, and conducted editing and revisions. PS conducted much of the error analysis as well as provided visualizations. AK worked on the analysis of the calibration constant tracking with cold plate temperature.

Competing interests. The authors declare that they have no conflict of interest.
Acknowledgements. The CATS instrument was funded by the ISS NASA Research Office (NRO), with CATS data products and processing algorithms funded by the NASA Science Mission Directorate (SMD). EARLINET acknowledges support from the European Union's Horizon 2020 research and innovation program under grant agreement no. 654109 .

Financial support. This research has been supported by the ISS NASA Research Office and the NASA Science Mission Directorate.

Review statement. This paper was edited by Alexander Kokhanovsky and reviewed by Franco Marenco and three anonymous referees.

\section{References}

Ansmann, A., Riebesell, M., Wandinger, U., Weitkamp, C., Voss, E., Lahmann, W., and Michaelis, W.: Combined Raman elastic backscatter LIDAR for vertical profiling of moisture, aerosol extinction, backscatter, and LIDAR ratio, Appl. Phys., B55, 18-28, https://doi.org/10.1007/BF00348608, 1992.

Avery, M., Winker, D., Heymsfield, A. J., Vaughan, M., Hu, Y., and Trepte, C.: Cloud ice water content retrieved from the CALIOP space-based lidar, Geophys. Res. Lett., 39, L05808, https://doi.org/10.1029/2011GL050545, 2012.

Baars, H., Kanitz, T., Engelmann, R., Althausen, D., Heese, B., Komppula, M., Preißler, J., Tesche, M., Ansmann, A., Wandinger, U., Lim, J.-H., Ahn, J. Y., Stachlewska, I. S., Amiridis, V., Marinou, E., Seifert, P., Hofer, J., Skupin, A., Schneider, F., Bohlmann, S., Foth, A., Bley, S., Pfüller, A., Giannakaki, E., Lihavainen, H., Viisanen, Y., Hooda, R. K., Pereira, S. N., Bortoli, D., Wagner, F., Mattis, I., Janicka, L., Markowicz, K. M., Achtert, P., Artaxo, P., Pauliquevis, T., Souza, R. A. F., Sharma, V. P., van Zyl, P. G., Beukes, J. P., Sun, J., Rohwer, E. G., Deng, R., Mamouri, R.-E., and Zamorano, F.: An overview of the first decade of PollyNET: an emerging network of automated Raman-polarization lidars for continuous aerosol profiling, Atmos. Chem. Phys., 16, 5111-5137, https://doi.org/10.5194/acp16-5111-2016, 2016.

Campbell, J. R., Vaughan, M. A., Oo, M., Holz, R. E., Lewis, J. R., and Welton, E. J.: Distinguishing cirrus cloud presence in autonomous lidar measurements, Atmos. Meas. Tech., 8, 435449, https://doi.org/10.5194/amt-8-435-2015, 2015.

Christian, K., Wang, J., Ge, C., Peterson, D., Hyer, E. J., Yorks, J., and McGill, M.: Radiative forcing and stratospheric warming of pyrocumulonimbus smoke aerosols: first modeling results with multi-sensor (EPIC, CALIPSO, CATS) views from space, Geophys. Res. Lett., 46, 10061-10071, https://doi.org/10.1029/2019GL082360, 2019.

Collins, R. T. H. and Russell, P. B.: Lidar measurement of particles and gases by elastic backscattering and differential absorption, Laser Monitoring of the Atmosphere, in: Topics in Applied Physics, 14, edited by: Hinkley, E. D., Springer-Verlag, Berlin, 71-151, https://doi.org/10.1007/3-540-07743-X_18, 1976.

D’Amico, G., Amodeo, A., Baars, H., Binietoglou, I., Freudenthaler, V., Mattis, I., Wandinger, U., and Pappalardo, G.: 
EARLINET Single Calculus Chain - overview on methodology and strategy, Atmos. Meas. Tech., 8, 4891-4916, https://doi.org/10.5194/amt-8-4891-2015, 2015.

D’Amico, G., Amodeo, A., Mattis, I., Freudenthaler, V., and Pappalardo, G.: EARLINET Single Calculus Chain - technical - Part 1: Pre-processing of raw lidar data, Atmos. Meas. Tech., 9, 491507, https://doi.org/10.5194/amt-9-491-2016, 2016.

Del Guasta, M.: Errors in the retrieval of thin cloud optical parameters obtained with a two boundary algorithm, Appl. Opt., 37, 5522-5540, 1998.

Dolinar, E. K., Campbell, J. R., Lolli, S., Ozog, S. C., Yorks, J. E., Camacho, C., Gu, Y., Bucholtz, A., and McGill, M. J.: Sensitivities in Satellite Lidar-derived Estimates of Top-of-theAtmosphere Optically-Thin Cirrus Cloud Radiative Forcing: A Case Study, Geophys. Res. Lett., in review, 2019.

Engelmann, R., Kanitz, T., Baars, H., Heese, B., Althausen, D., Skupin, A., Wandinger, U., Komppula, M., Stachlewska, I. S., Amiridis, V., Marinou, E., Mattis, I., Linné, H., and Ansmann, A.: The automated multiwavelength Raman polarization and water-vapor lidar Polly ${ }^{\mathrm{XT}}$ : the neXT generation, Atmos. Meas. Tech., 9, 1767-1784, https://doi.org/10.5194/amt-9-1767-2016, 2016.

Fernald, F.: Analysis of atmospheric lidar observations - Some comments, Appl. Opt., 23, 652-653, https://doi.org/10.1364/AO.23.000652, 1984.

Garnier, A., Pelon, J., Vaughan, M. A., Winker, D. M., Trepte, C. R., and Dubuisson, P.: Lidar multiple scattering factors inferred from CALIPSO lidar and IIR retrievals of semi-transparent cirrus cloud optical depths over oceans, Atmos. Meas. Tech., 8, 27592774, https://doi.org/10.5194/amt-8-2759-2015, 2015.

Gelaro, R., McCarty, W., Suárez, M. J., Todling, R., Molod, A., Takacs, L., Randles, C. A., Darmenov, A., Bosilovich, M. G., Reichle, R., Wargan, K., Coy L., Cullather, R., Draper, C., Akella, S., Buchard, V., Conaty, A., da Silva, A. M., Gu, W., Kim, G., Koster, R., Lucchesi, R., Merkova, D., Nielsen, J. E., Partyka, G., Pawson, S., Putman, W., Rienecker, M., Schubert, S. D., Sienkiewicz, M., and Zhao, B.: The Modern-Era Retrospective Analysis for Research and Applications, Version 2 (MERRA-2), J. Climate, 30, 5419-5454, https://doi.org/10.1175/JCLI-D-160758.1, 2017.

Groß, S., Esselborn, M., Abicht, F., Wirth, M., Fix, A., and Minikin, A.: Airborne high spectral resolution lidar observation of pollution aerosol during EUCAARI-LONGREX, Atmos. Chem. Phys., 13, 2435-2444, https://doi.org/10.5194/acp13-2435-2013, 2013.

Haarig, M., Engelmann, R., Ansmann, A., Veselovskii, I., Whiteman, D. N., and Althausen, D.: $1064 \mathrm{~nm}$ rotational Raman lidar for particle extinction and lidar-ratio profiling: cirrus case study, Atmos. Meas. Tech., 9, 4269-4278, https://doi.org/10.5194/amt9-4269-2016, 2016.

Haarig, M., Ansmann, A., Althausen, D., Klepel, A., Groß, S., Freudenthaler, V., Toledano, C., Mamouri, R.-E., Farrell, D. A., Prescod, D. A., Marinou, E., Burton, S. P., Gasteiger, J., Engelmann, R., and Baars, H.: Triple-wavelength depolarizationratio profiling of Saharan dust over Barbados during SALTRACE in 2013 and 2014, Atmos. Chem. Phys., 17, 10767-10794, https://doi.org/10.5194/acp-17-10767-2017, 2017.

Hair, J. W., Hostetler, C. A., Cook, A. L., Harper, D. B., Ferrare, R. A., Mack, T. L., Welch, W., Izquierdo, L. R., and
Hovis, F. E.: Airborne High Spectral Resolution Lidar for pro?ling aerosol optical properties, Appl. Opt., 47, 6734-6752, https://doi.org/10.1364/AO.47.006734, 2008.

Holben, B. N., Eck, T. F., Slutsker, I., Tanre, D., Buis, J. P., Setzer, A., Vermote, E., Reagan, J. A., Kaufman, Y., Nakajima, T., Lavenue, F., Jankowiak, I., and Smirnov, A.: AERONET - A federated instrument network and data archive for aerosol characterization, Remote Sens. Environ., 66, 1-16, https://doi.org/10.1016/S0034-4257(98)00031-5, 1998.

Hostetler, C. A., Liu, Z., Reagan, J. A., Vaughan, M. A., Winker, D. M., Osborn, M. T., Hunt, W. H., Powell, K. A., and Trepte, C. R.: CALIPSO algorithm theoretical basis document, PC-SCI201, available at: https://www-calipso.larc.nasa.gov/resources/ project_documentation.php (last access: 1 August 2019), 2005.

Hughes, E. J., Yorks, J. E., Krotkov, N. A., da Silva. A. M., and McGill, M.: Using CATS near-realtime lidar observations to monitor and constrain volcanic sulfur dioxide $\left(\mathrm{SO}_{2}\right)$ forecasts, Geophys. Res. Lett., 43, 11089-11097, https://doi.org/10.1002/2016GL070119, 2016.

Hunt, W. H., Winker, D. M., Vaughan, M. A., Powell, K. A., Lucker, P. L., and Weimer, C.: CALIPSO lidar description and performance assessment, J. Atmos. Ocean. Tech., 26, 1214-1228, https://doi.org/10.1175/ 2009JTECHA1223.1, 2009.

Iqbal, M.: An Introduction to Solar Radiation, Academic Press, New York, NY, 408 pp., 1983.

Kar, J., Vaughan, M. A., Lee, K.-P., Tackett, J. L., Avery, M. A., Garnier, A., Getzewich, B. J., Hunt, W. H., Josset, D., Liu, Z., Lucker, P. L., Magill, B., Omar, A. H., Pelon, J., Rogers, R. R., Toth, T. D., Trepte, C. R., Vernier, J.-P., Winker, D. M., and Young, S. A.: CALIPSO lidar calibration at $532 \mathrm{~nm}$ : version 4 nighttime algorithm, Atmos. Meas. Tech., 11, 1459-1479, https://doi.org/10.5194/amt-11-1459-2018, 2018.

Klett, J.: Stable analytical inversion solution for processing lidar returns, Appl. Opt., 20, 211-220, https://doi.org/10.1364/AO.20.000211, 1981.

Kremser, S., Thomason, L. W., von Hobe, M., Hermann, M., Deshler, T., Timmreck, C., Toohey, M., Stenke, A., Schwarz, J. P., Weigel, R., Fueglistaler, S., Prata, F. J., Vernier, J., Schlager, H., Barnes, J. E., Antuña-Marrero, J., Fairlie, D., Palm, M., Mahieu, E., Notholt, J., Rex, M., Bingen, C., Vanhellemont, F., Bourassa, A., Plane, J. M. C., Klocke, D., Carn, S. A, Clarisse, L., Trickl, T., Neely, R., James, A. D., Rieger, L., Wilson, J. C., and Meland, B.: Stratospheric aerosol - Observations, processes, and impact on climate, Rev. Geophys., 54, 278-335, https://doi.org/10.1002/2015RG000511, 2016.

Lee, L., Zhang, J., Reid, J. S., and Yorks, J. E.: Investigation of CATS aerosol products and application toward global diurnal variation of aerosols, Atmos. Chem. Phys., 19, 12687-12707, https://doi.org/10.5194/acp-19-12687-2019, 2019.

Liou, K. N., Takano, Y., and Yang, P.: Light scattering and radiative transfer in ice crystal clouds: Applications to climate research, in: Light Scattering by Nonspherical Particles, edited by: Mishchenko, M., Hovenier, J. W., and Travis, L. D., Academic, San Diego, Calif., 417-449, 2000.

Liu, Z., McGill, M., Hu, Y., Hostetler, C. A., Vaughan, M., and Winker, D.: Validating lidar depolarization calibration using solar radiation scattered by ice clouds, IEEE T. Geosci. Remote, 1, 157-161, https://doi.org/10.1109/LGRS.2004.829613, 2004. 
Mamouri, R. E., Amiridis, V., Papayannis, A., Giannakaki, E., Tsaknakis, G., and Balis, D. S.: Validation of CALIPSO spaceborne-derived attenuated backscatter coefficient profiles using a ground-based lidar in Athens, Greece, Atmos. Meas. Tech., 2, 513-522, https://doi.org/10.5194/amt-2-513-2009, 2009.

Mattis, I., D’Amico, G., Baars, H., Amodeo, A., Madonna, F., and Iarlori, M.: EARLINET Single Calculus Chain - technical - Part 2: Calculation of optical products, Atmos. Meas. Tech., 9, 30093029, https://doi.org/10.5194/amt-9-3009-2016, 2016.

McGill, M. J., Hlavka, D. L., Hart, W. D., Spinhirne, J. D., Scott, V. S., and Schmid, B.: The Cloud Physics Lidar: Instrument description and initial measurement results, Appl. Opt., 41, 3725-3734, https://doi.org/10.1364/AO.41.003725, 2002.

McGill, M. J., Hlavka, D. L., Hart, W. D., Welton, E. J., and Campbell, J. R.: Airborne lidar measurements of aerosol optical properties during SAFARI-2000, J. Geophys. Res., 108, 8493, https://doi.org/10.1029/2002JD002370, 2003.

McGill, M. J., Vaughan, M. A., Trepte, C. R., Hart, W. D., Hlavka, D. L., Winker, D. M., and Keuhn, R.: Airborne validation of spatial properties measured by the CALIPSO lidar, J. Geophys. Res., 112, D20201, https://doi.org/10.1029/2007JD008768, 2007.

McGill, M. J., Yorks, J. E., Scott, V. S., Kupchock, A. W., and Selmer, P. A.: The Cloud-Aerosol Transport System (CATS): A technology demonstration on the International Space Station, Proc. Spie., 9612, https://doi.org/10.1117/12.2190841, 2015.

Mona, L., Pappalardo, G., Amodeo, A., D’Amico, G., Madonna, F., Boselli, A., Giunta, A., Russo, F., and Cuomo, V.: One year of CNR-IMAA multi-wavelength Raman lidar measurements in coincidence with CALIPSO overpasses: Level 1 products comparison, Atmos. Chem. Phys., 9, 7213-7228, https://doi.org/10.5194/acp-9-7213-2009, 2009.

Noel, V., Chepfer, H., Chiriaco, M., and Yorks, J.: The diurnal cycle of cloud profiles over land and ocean between $51^{\circ} \mathrm{S}$ and $51^{\circ} \mathrm{N}$, seen by the CATS spaceborne lidar from the International Space Station, Atmos. Chem. Phys., 18, 9457-9473, https://doi.org/10.5194/acp-18-9457-2018, 2018.

Papagiannopoulos, N., Mona, L., Alados-Arboledas, L., Amiridis, V., Baars, H., Binietoglou, I., Bortoli, D., D’Amico, G., Giunta, A., Guerrero-Rascado, J. L., Schwarz, A., Pereira, S., Spinelli, N., Wandinger, U., Wang, X., and Pappalardo, G.: CALIPSO climatological products: evaluation and suggestions from EARLINET, Atmos. Chem. Phys., 16, 2341-2357, https://doi.org/10.5194/acp-16-2341-2016, 2016.

Papayannis, A., Mamouri, R. E., Amiridis, V., Kazadzis, S., Pérez García-Pando, C., Tsaknakis, G., Kokkalis, P., and Baldasano, J.: Systematic lidar observations of Saharan dust layers over Athens, Greece in the frame of EARLINET project (2004-2006), Ann. Geophys., 27, 3611-3620, https://doi.org/10.5194/angeo27-3611, 2009.

Platt, C. M.: Lidar and radiometric observations of cirrus clouds, J. Atmos. Sci., 30, 1191-1204, https://doi.org/10.1175/1520-0469, 1973.

Platt, C. M.: Remote sounding of high clouds: I. Calculation of visible and infrared optical properties from lidar and radiometer measurements, J. App. Met., 18, 1130-1143, doi.org/10.1175/1520-0450, 1979.

Povey, A. C., Grainger, R. G., Peters, D. M., and Agnew, J. L.: Retrieval of aerosol backscatter, extinction, and lidar ratio from Ra- man lidar with optimal estimation, Atmos. Meas. Tech., 7, 757776, https://doi.org/10.5194/amt-7-757-2014, 2014.

Powell, K. A., Hostetler, C. A., Liu, Z., Vaughan, M. A., Kuehn, R. E., Hunt, W. H., Lee, K., Trepte, C. R., Rogers, R. R., Young, S. A., and Winker, D. M.: CALIPSO Lidar Calibration Algorithms: Part I - Nighttime $532 \mathrm{~nm}$ Parallel Channel and $532 \mathrm{~nm}$ Perpendicular Channel, J. Atmos. Ocean. Tech., 26, 2015-2033, 2009.

Proestakis, E., Amiridis, V., Marinou, E., Binietoglou, I., Ansmann, A., Wandinger, U., Hofer, J., Yorks, J., Nowottnick, E., Makhmudov, A., Papayannis, A., Pietruczuk, A., Gialitaki, A., Apituley, A., Szkop, A., Muñoz Porcar, C., Bortoli, D., Dionisi, D., Althausen, D., Mamali, D., Balis, D., Nicolae, D., Tetoni, E., Liberti, G. L., Baars, H., Mattis, I., Stachlewska, I. S., Voudouri, K. A., Mona, L., Mylonaki, M., Perrone, M. R., Costa, M. J., Sicard, M., Papagiannopoulos, N., Siomos, N., Burlizzi, P., Pauly, R., Engelmann, R., Abdullaev, S., and Pappalardo, G.: EARLINET evaluation of the CATS Level 2 aerosol backscatter coefficient product, Atmos. Chem. Phys., 19, 11743-11764, https://doi.org/10.5194/acp-19-11743-2019, 2019.

Rajapakshe, C., Zhang, Z., Yorks, J. E., Yu, H., Tan, Q., Meyer, K., and Platnick, S.: Seasonally transported aerosol layers over southeast Atlantic are closer to underlying clouds than previously reported, Geophys. Res. Lett., 44, 5818-5825, https://doi.org/10.1002/2017GL073559, 2017.

Reagan, J. A., Wang, X., and Osborn, M. T.: Spaceborne lidar calibration from cirrus and molecular backscatter returns, IEEE T. Geosci. Remote, 40, 2285-2290, https://doi.org/10.1109/TGRS.2002.802464, 2002.

Russell, P. B., Swissler, T. J., and McCormick, M. P.: Methodology for error analysis and simulation of lidar aerosol measurements, Appl. Opt., 18, 3783-3797, 1979.

SPARC-ASAP: Assessment of Stratospheric Aerosol Properties (ASAP), WCRP-124, WMO/TD No. 1295, SPARC Rep. 4, 348 pp., 2006.

Spinhirne, J. D., Chudamani, S., Cavanaugh, J. F., and Bufton, J. L.: Aerosol and cloud backscatter at $1.06,1.54$, and $0.53 \mathrm{~mm}$ by airborne hard-target-calibrated Nd:YAG/methane Raman lidar, Appl. Opt., 36, 3475-3490, 1997.

Spinhirne, J. D., Palm, S. P., Hart, W. D., Hlavka, D. L., and Welton, E. J.: Cloud and aerosol measurements from GLAS: Overview and initial results, Geophys. Res. Lett., 32, L22S03, https://doi.org/10.1029/2005GL023507, 2005.

Vaughan, M. A., Liu, Z., McGill, M. J., Hu, Y., and Obland, M. D.: On the Spectral Dependence of Backscatter from Cirrus Clouds: Assessing CALIOP's $1064 \mathrm{~nm}$ Calibration Assumptions Using Cloud Physics Lidar Measurements, J. Geophys. Res., 115, D14206, https://doi.org/10.1029/2009JD013086, 2010.

Vaughan, M., Garnier, A., Josset, D., Avery, M., Lee, K.-P., Liu, Z., Hunt, W., Pelon, J., Hu, Y., Burton, S., Hair, J., Tackett, J. L., Getzewich, B., Kar, J., and Rodier, S.: CALIPSO lidar calibration at $1064 \mathrm{~nm}$ : version 4 algorithm, Atmos. Meas. Tech., 12, 51-82, https://doi.org/10.5194/amt-12-51-2019, 2019.

Vernier, J. P., Pommereau, J. P., Garnier, A., Pelon, J., Larsen, N., Nielsen, J., Christiansen, T., Cairo, F., Thomason, L. W., Leblanc, T., and McDermid, I. S.: Tropical stratospheric aerosol layer from CALIPSO lidar observations, J. Geophys. Res., 114, D00H10, https://doi.org/10.1029/2009JD011946, 2009. 
Vernier, J.-P., Fairlie, T. D., Natarajan, M., Wienhold, F. G., Martinsson, B. G., Crumeyrolle S., Thomason, L. W., and Bedka, K. M.: Increase in upper tropospheric and lower stratospheric aerosol levels and its potential connection with Asian pollution, J. Geophys. Res., 120, 1608-1619, https://doi.org/10.1002/2014JD022372, 2015.

Wang, J., Ge, C., Yang, Z. F., Hyer, E. J., Reid, J. S., Chew, B.-N., Mahmud, M., Zhang, Y., and Zhang, M.: Mesoscale Modeling of Smoke Transport over the Southeast Asian Maritime Continent: Interplay of Sea Breeze, Trade Wind, Typhoon, and Topography, Atmos. Res., 122, 486-503, https://doi.org/10.1016/j.atmosres.2012.05.009, 2013.

Welton, E. J., Campbell, J. R., Spinhirne, J. D., Scott, V. S.: Global monitoring of clouds and aerosols using a network of micropulse lidar systems, Proc. Spie., 4153, https://doi.org/10.1117/12.417040, 2001.

Welton, E. J. and Campbell, J. R.: Micropulse Lidar Signals: Uncertainty analysis, J. Atmos. Ocean. Tech., 19, 2089-2094, https://doi.org/10.1175/15200426(2002)019<2089:MLSUA<2.0.CO;2, 2002.

Welton, E. J., Voss, K. J., Quinn, P. K., Flatau, P. J., Markowicz, K., Campbell, J. R., Spinhirne, J. D., Gordon, H. R., and Johnson, J. E.: Measurements of aerosol vertical profiles and optical properties during INDOEX 1999 using micropulse lidars, J. Geophys. Res., 107, 8019, https://doi.org/10.1029/2000JD000038, 2002.

Whiteman, D. N.: Examination of the traditional Raman lidar technique, 1. Evaluating the temperaturedependent lidar equations, Appl. Opt., 42, 2571-2592, https://doi.org/10.1364/AO.42.002571, 2003.

Winker, D.: Accounting for multiple scattering in retrievals from space lidar, Proc. Spie., 5059, 128-139, 2003.

Winker, D. M., Couch, R. H., and McCormick, P. M.: An overview of LITE: NASA's Lidar In-space Technology Experiment, Proc. IEEE., 84, 1-17, 1996.

Winker, D. M., Pelon, J., Coakley, J. A., Ackerman, S. A., Charlson, R. J., Colarco, P. R., Flamant, P., Fu, Q., Hoff, R. M., Kittaka, C., Kubar, T. L., Le Treut, H., Mccormick, P. M., Mégie, G., Poole, L., Powell, K., Trepte, C., Vaughan, M. A., and Wielicki, B. A.: The CALIPSO Mission, B. Am. Meteorol. Soc., 91, 1211-1230, https://doi.org/10.1175/2010BAMS3009.1, 2010.
Yang, Z., Wang, J., Ichoku, C., Hyer, E., and Zeng, J.: Mesoscale modeling and satellite observation oftransport and mixing of smoke and dust particles over northern sub-Saharan African region, J. Geophys. Res. Atmos., 118, 12139-12157, https://doi.org/10.1002/2013JD020644, 2013.

Yorks, J. E., Hlavka, D. L., Hart, W. D., and McGill, M. J.: Statistics of Cloud Optical Properties from Airborne Lidar Measurements, J. Atmos. Ocean. Tech., 28, 869-883, https://doi.org/10.1175/2011JTECHA1507.1, 2011.

Yorks, J. E., Palm, S. P., Hlavka, D. L., McGill, M. J., Nowottnick, E., Selmer, P., and Hart, W. D.: The Cloud-Aerosol Transport System (CATS) algorithm theoretical basis document, available at: http://cats.gsfc.nasa.gov/media/docs/CATS_ATBD.pdf (last access: 1 September 2019), 2015.

Yorks, J. E., McGill, M. J., Palm, S. P., Hlavka, D. L., Selmer, P. A., Nowottnick, E. P., Vaughan, M. A., Rodier, S. D., and Hart, W. D.: An overview of the CATS level 1 processing algorithms and data products, Geophys. Res. Lett., 43, 4632-4639, https://doi.org/10.1002/2016GL068006, 2016.

Yorks, J. E., Nowottnick, E., Selmer, P. A., Rodier, S. D., Vaughan, M. A, Dacic, N., McGill, M. J., and Palm, S. P..: CATS level 2 vertical feature mask algorithms and data products: An overview and initial assessment, Atmos. Meas. Tech. Discuss., in preparation, 2019.

Young, S., Vaughan, M. A., Kuehn, R. E., and Winker, D. M.: The Retrieval of Profiles of Particulate Extinction from Cloud-Aerosol Lidar Infrared Pathfinder Satellite Observations (CALIPSO) Data: Uncertainty and Error Sensitivity Analyses, J. Atmos. Ocean. Tech., 30, 395-428, https://doi.org/10.1175/JTECH-D-12-00046.1, 2013.

Young, S., Vaughan, M. A., Kuehn, R. E., and Winker, D. M.: The Retrieval of Profiles of Particulate Extinction from Cloud-Aerosol Lidar Infrared Pathfinder Satellite Observations (CALIPSO) Data: Uncertainty and Error Sensitivity Analyses - Corrigendum, J. Atmos. Ocean. Tech., 33, 1795-1798, https://doi.org/10.1175/JTECH-D-16-0081.1, 2016.

Young, S. A., Vaughan, M. A., Garnier, A., Tackett, J. L., Lambeth, J. D., and Powell, K. A.: Extinction and optical depth retrievals for CALIPSO's Version 4 data release, Atmos. Meas. Tech., 11, 5701-5727, https://doi.org/10.5194/amt-11-5701-2018, 2018. 